\title{
Prediction of Bank Erosion in a Reach of the Sacramento River and its Mitigation with Groynes
}

\author{
A. Ercan - B. A. Younis
}

Received: 3 June 2008 / Accepted: 2 February 2009 /

Published online: 4 March 2009

(C) The Author(s) 2009. This article is published with open access at Springerlink.com

\begin{abstract}
The paper reports on the prediction of flow in a reach of the Sacramento River with focus on a part of the river's bank where serious erosion has occurred. The simulations were obtained using a three-dimensional Navier-Stokes solver which utilized body-fitted coordinates to represent the complex river bathymetry. Comparative predictions were obtained using a two-dimensional, depth-averaged formulation. Local (nested) mesh refinement was employed to provide the necessary resolution of the bank geometry in the region of interest. The study focuses on the assessment of the effectiveness of a particular arrangement of groynes which was found in physical model studies to significantly reduce the rate of erosion in the region under consideration. To validate the computational models, predictions were first obtained for the case of turbulent flow in a straight rectangular channel with one groyne. Measurements of velocity and boundary shear stress were used for model validation. For the reach of the Sacramento River under consideration, velocity measurements obtained in the large-scale physical model were also used to check the computational model prior to its use for prediction of the river flow with groynes. Here, too, both depth-averaged and three-dimensional computations were performed with the objective being to determine the influence of the groynes on the flow velocity. The bank erosion rate was estimated by coupling the 'excess shear stress' method to the computed mean velocity field. The results show that for the groynes configuration that was found optimal in the physical-model studies, and that was actually implemented in the Sacramento River, the groynes are effective in reducing the bank erosion of the affected zone but at the cost of transferring a far less severe problem further downstream.
\end{abstract}

Keywords Computational river mechanics • Computational fluid dynamics • Turbulent flows • Bank erosion • Groynes

\footnotetext{
A. Ercan · B. A. Younis $(\varangle)$

Department of Civil \& Environmental Engineering, University of California-Davis,

Davis, CA 95616 USA

e-mail: bayounis@ucdavis.edu
} 


\section{Nomenclature}

\begin{tabular}{|c|c|}
\hline$C_{\varepsilon_{1}}, C_{\varepsilon_{2}}, C_{\mu}$ & constants in the $k-\varepsilon$ model \\
\hline$d$ & sediment particle diameter \\
\hline$g$ & acceleration due to gravity \\
\hline$K$ & erodibility coefficient \\
\hline$k$ & turbulent kinetic energy \\
\hline$l$ & length scale representative of the energy-containing eddies \\
\hline$P_{k}$ & production rate of $k$ \\
\hline$P_{\varepsilon}$ & production rate of $\varepsilon$ \\
\hline$\overline{u_{i} u_{j}}$ & Reynolds-stress tensor \\
\hline$U_{i}$ & Cartesian velocity components \\
\hline$U, V, W$ & velocities in $\mathrm{x}, \mathrm{y}, \mathrm{z}$ directions \\
\hline$x_{i}$ & physical coordinates \\
\hline$x, y, z$ & streamwise, spanwise and depthwise directions \\
\hline$V_{x y}$ & velocity magnitude in depth averaged computation \\
\hline$v_{t}$ & eddy viscosity \\
\hline$\varepsilon$ & turbulence energy dissipation \\
\hline$\phi$ & angle of repose for the sediment \\
\hline$\theta_{1}$ & slope of the bank \\
\hline$\sigma_{k}, \sigma_{\varepsilon}$ & constants of $k-\varepsilon$ model \\
\hline$\tau$ & bed shear stress \\
\hline$\tau_{\mathrm{c}}$ & critical shear stress \\
\hline$\tau_{\mathrm{c} 21}$ & $\begin{array}{l}\text { critical shear stress for a particle of diameter } d_{2} \text { resting on a bed of } \\
\text { particles of diameter } d_{1}\end{array}$ \\
\hline$\tau_{\mathrm{WC}}$ & critical shear stress on the bank \\
\hline$\xi$ & fluvial erosion rate \\
\hline
\end{tabular}

\section{Introduction}

The ability to accurately predict the physical processes that lead to riverbank erosion is very important since erosion can be the cause of significant environmental and economical problems such as land loss, hazards to aquatic habitats, and damage to hydraulic structures such as bridge piers and abutments. Erosion, if extensive and not mitigated in some way, can also be a source of sediment load in rivers. In the Sacramento River, for example, approximately $60 \%$ of the total sediment inflow is attributable directly to bank erosion (US Army Corps of Engineers 1983). The physical processes involved are quite complex and involve the combined actions of weathering, fluvial erosion, and geotechnical instability (Thorne 1982; Lawler 1992). In addition, factors such as the soil properties, the frequency of freeze-thaw, the stratigraphy of the bank structure, the type and density of vegetation and the grain size of the bed sediment at the toe of the bank significantly influence the erosion processes. Pizzuto and Meckelnburg (1989) provide a comprehensive review of studies on river migration due to erosion in which some of these factors are considered.

There have been several studies that attempted to relate the rate of bank retreat to channel characteristics. Notable among these are those by Brice (1982), Nanson and Hickin (1983), Ikeda et al. (1981) and Parker (1983). Brice (1982) showed that 
the rate of bank retreat increases with increasing channel width while Nanson and Hickin (1983) have found a strong correlation between the channel curvature and the rate of bank retreat. Ikeda et al. (1981) assumed that the rate of the bank retreat is proportional to the difference between the near-bank depth-averaged velocity and the reach-averaged velocity. Parker (1983) developed a relationship between the migration rate and channel curvature. He included a factor that parameterized the role of the secondary currents that develop in planes normal to the main direction of flow. Hasegawa (1989) related the bank erosion rate to the excess velocity which was defined as the difference between near-bank and centerline depth-averaged flow velocity. A generalized bank erosion coefficient was also defined as a function of both hydraulic parameters as well as geotechnical properties of the bank. Recently, Darby and Thorne (1996), Nagata et al. (2000), Duan et al. (2001), Darby et al. (2002), Olsen (2003), and Jang and Shimizu (2005) have developed hydrodynamic and sediment transport models with channel width adjustments. Darby and Thorne (1996) simulated channel widening by coupling bank stability with flow and sediment transport algorithms and used a probabilistic approach to estimate the longitudinal extent of mass failures. Their model is applicable to non-cohesive sand-bed channels with cohesive bank materials. Both Nagata et al. (2000) and Jang and Shimizu (2005) applied the empirical approach by Hasegawa (1984) to predict bank erosion processes. According to this approach, bank erosion occurs when the cross-sectional gradient of the bank slope becomes steeper than the submerged angle of repose of the bank material. Darby et al. (2002) developed a numerical model for meandering channels with erodible cohesive banks. Their model was shown to be capable of simulating the deposition of failed bank material debris at the toe of the bank and its subsequent removal. Olsen (2003) used a 3D model to compute the development of meandering pattern in an initially straight alluvial channel. The bed level changes were computed by using the sediment continuity equation.

Although fluvial erosion drives bank retreat directly by removal of material from the bank face and by triggering mass instability (ASCE Task Committee 1998), detailed knowledge of the flow behavior in the near-bank regions remains very limited. On the other hand, a significant portion of the uncertainties associated with the computational modeling of near-bank flow is directly attributable to inadequate surface definition and inadequacies in the computational meshes that are used to resolve the flow there. These and other factors which contribute to uncertainties in the computational modeling of river-scale flows are considered in detail in Ercan and Younis (2008) where it was found, for example, that the choice of method used to interpolate field survey data in order to define the computational flow domain exerts a considerable influence on the quality of the computed results. In this study, we use the best practices to emerge from that earlier study to obtain predictions of the flow field and the associated bank erosion. Both two-dimensional (depth-averaged) and three-dimensional simulations were performed and their results compared; the former because depth-averaged simulations are commonly used in river applications (e.g. Novikov and Bagtzoglou 2006) and the latter in order to assess the importance of flow skewness on bank-erosion processes. The focus is on a region of the Sacramento River, immediately upstream of a bridge pier and abutment, where significant bank erosion has occurred. A strategy for mitigation of this problem was proposed in the form of groynes that would act to deflect fast-moving flow away from the eroding bank. As such solutions often resolve the erosion problem at one location in the river only at the cost of transferring it further downstream, a large-scale 
physical model study was performed to check the suitability of several alternative design configurations having different numbers of groynes, arranged at different orientation relative to the bank. In this study, we conduct numerical simulations to check the validity of the most optimal configuration to be identified in these tests, and which was finally deployed in the river. Measurements of mean-flow velocities were obtained in the physical model and these are used here to check the models results. Bank erosion rates, which were not obtained in the physical model study, are estimated in the present simulations using the excess shear stress method of Partheniades (1965). Bank erosion computations, before and after the deployment of the groynes, are compared with field observations. The effects of turbulence, another important factor in determining erosion rates, are accounted for in the predictions using the two-equation $k-\varepsilon$ model of turbulence. Details of this model and of the computational procedure are given next.

\section{Computational Model}

\subsection{Mean-flow and Turbulence-model Equations}

The computational model used in this study is based on the solution of the continuity and the Reynolds-Averaged Navier-Stokes equations in both two- and three dimensions (hereafter 2D and 3D). These equations are written in Cartesian-tensor notation as:

$$
\begin{gathered}
\frac{\partial U_{i}}{\partial x_{i}}=0 \\
\frac{\partial U_{i}}{\partial t}+U_{j} \frac{\partial U_{i}}{\partial x_{j}}=g_{i}-\frac{1}{\rho} \frac{\partial P}{\partial x_{i}}+\frac{\partial}{\partial x_{j}}\left(v \frac{\partial U_{i}}{\partial x_{j}}-\overline{u_{i} u_{j}}\right)
\end{gathered}
$$

In the above, $U_{i}$ is the mean-flow velocity vector, $P$ is the static pressure and repeated indices imply summation.

The unknown Reynolds stresses that appear in Eq. 2 were obtained from Boussinesq's linear stress-strain hypothesis:

$$
-\overline{u_{i} u_{j}}=v_{t}\left(\frac{\partial U_{i}}{\partial x_{j}}+\frac{\partial U_{j}}{\partial x_{i}}\right)-\delta_{i j} k
$$

The eddy viscosity in Eq. 3 was determined by using the standard form of the widely-used $k-\varepsilon$ model of turbulence:

$$
\begin{gathered}
v_{t}=C_{\mu} \frac{k^{2}}{\varepsilon} \\
\frac{\partial k}{\partial t}+U_{i} \frac{\partial k}{\partial x_{i}}=\frac{\partial}{\partial x_{i}}\left(\frac{v_{t}}{\sigma_{k}} \frac{\partial k}{\partial x_{i}}\right)+P_{k}-\varepsilon \\
\frac{\partial \varepsilon}{\partial t}+U_{i} \frac{\partial \varepsilon}{\partial x_{i}}=\frac{\partial}{\partial x_{i}}\left(\frac{v_{t}}{\sigma_{\varepsilon}} \frac{\partial \varepsilon}{\partial x_{i}}\right)+C_{\varepsilon_{1}} \frac{\varepsilon}{k} P_{k}-C_{\varepsilon_{2}} \frac{\varepsilon^{2}}{k}
\end{gathered}
$$


where

$$
P_{k}=v_{t} \frac{\partial U_{i}}{\partial x_{j}}\left(\frac{\partial U_{i}}{\partial x_{j}}+\frac{\partial U_{j}}{\partial x_{i}}\right)
$$

The turbulence-model coefficients $\left(C_{\mu}, \sigma_{k}, \sigma_{\varepsilon}, C_{\varepsilon_{1}}, C_{\varepsilon_{2}}\right)$ were assigned their usual values of $(0.09,1.0,1.3,1.44,1.92)$ respectively (Launder and Spalding 1972).

A schematic of the computational cross-sections is shown in Fig. 1. The boundary conditions used in the present computations were as follows: At inlet, a velocity distribution consistent with that of a fully-developed three-dimensional turbulent boundary layer was specified with the cross-stream profiles of mean velocity prescribed using a power-law distribution. The maximum velocity $\left(U_{m}\right)$ was set equal to $1.3 \mathrm{~m} / \mathrm{s}$ so that the integrated velocity profile yielded the same flow rate as in the physical-model study. The profiles of $k$ and $\varepsilon$ were specified with the assumption that the relative turbulence intensity $\left(u^{\prime} / U_{m}\right)$ and the turbulence length scale (1) at inlet were equal to 0.1 and $0.001 \mathrm{~m}$, respectively. Thereafter, $k$ was deduced from $k=\overline{u^{2}}$ and $\varepsilon$ was deduced from the relation $\varepsilon=C k^{3 / 2} / 1$ where 1 is a length scale representative of the energy-containing eddies. The free surface was treated as a plane of symmetry in the three-dimensional calculations. At the exit plane, the flow was assumed to be fully developed and hence the streamwise gradients of all dependent variables were set equal to zero. At the riverbed, the no-slip wall boundary condition was applied thereby the velocities tangential and normal to the walls were set to zero and the flux of the streamwise velocity component deduced from experimental correlations for bed friction. This treatment, which is typically referred to as the 'wall functions' approach, requires the specification of an
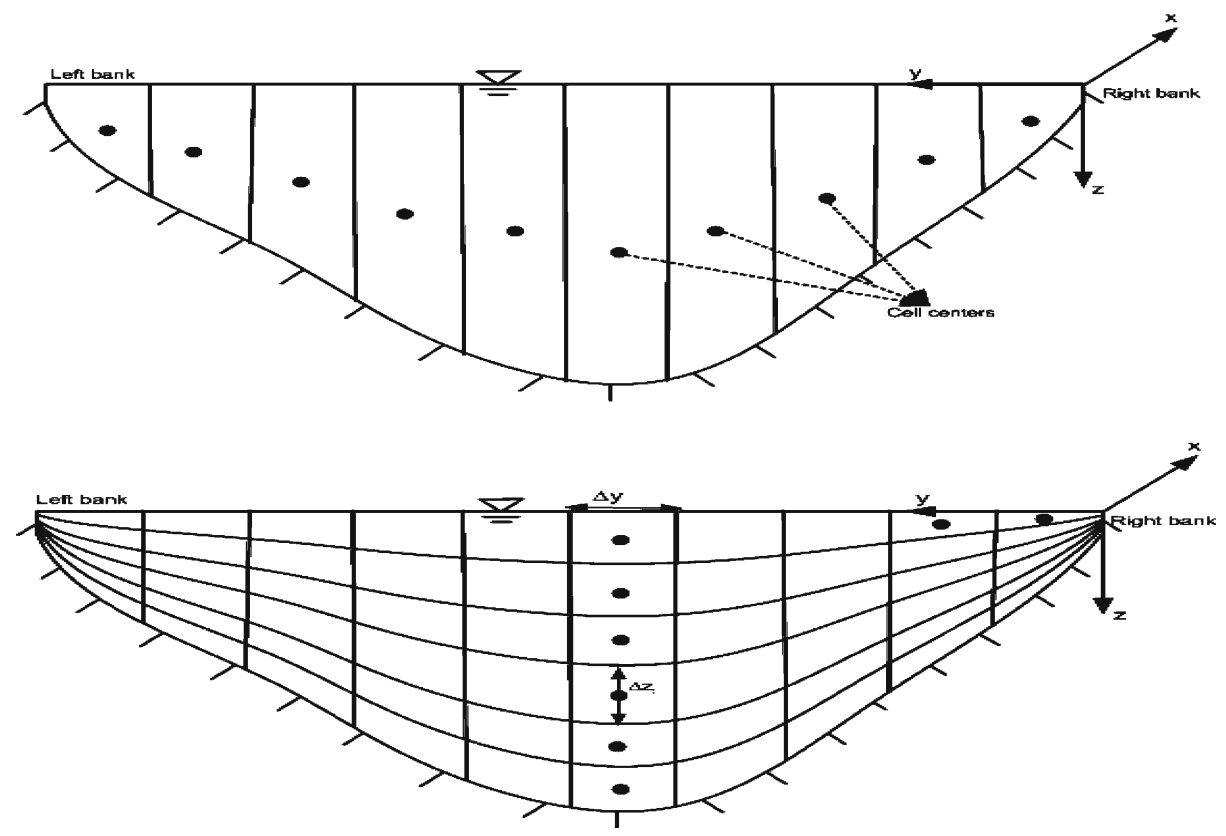

Fig. 1 Schematic of cross-sections in the 2D and 3D computational model 
appropriate bed resistance formula. A number of alternative formulae are available (see, e.g. Tsihrintzis and Madiedo 2000) and the particular one used here is based on the assumption that the mean velocity close to the wall can be described with the universal logarithmic law of the wall. In terms of implementation, the near wall viscosity was replaced by the value $\mu_{w}$ determined from either the laminar relation appropriate to the viscous sublayer or the universal logarithmic velocity profile appropriate for the fully turbulent regions away from the wall:

$$
\begin{gathered}
\mu_{w}=\frac{y^{+}}{u^{+}} \mu \\
\text { where } u^{+}=\left\{\begin{array}{cc}
y^{+}, & y^{+}<y_{v}^{+} \\
\frac{1}{\kappa} \ln \left(E y^{+}\right), & y^{+} \geq y_{v}^{+}
\end{array}\right.
\end{gathered}
$$

$\kappa$ is the von Karman constant $(=0.41), E$ is the logarithmic profile constant $(=9)$, and $y^{+}$is the dimensionless distance to the wall, obtained as an empirical fit to turbulent flow data:

$$
y^{+}=\frac{\rho C_{\mu}^{1 / 4} k_{P_{0}}^{1 / 2} \delta n_{P_{0}}}{\mu}
$$

Here $\mu$ is the molecular viscosity, $C_{\mu}$ is the turbulence model coefficient, $\delta n$ is the normal distance from the wall, $P_{0}$ denotes the center of the control volume next to the wall. The viscous sub-layer thickness $y^{+}$is the larger root of the non-linear equation

$$
y_{v}^{+}=\frac{1}{\kappa} \ln \left(E y_{v}^{+}\right)
$$

\subsection{Model for Bank Erosion}

In this study, the rate of bank erosion is obtained by coupling the solution of the Reynolds-Averaged Navier-Stokes equations to the excess shear stress approach of the Partheniades (1965). In this approach, the fluvial erosion rate is related to the excess shear stress through a simple power relation of the form:

$$
\xi=K\left(\tau-\tau_{\mathrm{c}}\right)^{a}
$$

where $\xi$ is the erosion rate in $\mathrm{m} / \mathrm{s}, K$ is an erodibility coefficient in $\mathrm{m}^{3} \mathrm{~N}^{-1} \mathrm{~s}^{-1}$ and $\tau-\tau_{\mathrm{c}}$ is the excess shear stress ( $\tau$ being the bed shear stress and $\tau_{\mathrm{c}}$ is the critical shear stress, both in Pa). In Eq. 11, ' $a$ ' is an exponent whose value is often taken to be 1.0. The critical shear stress in the same equation is calculated from Shields' curve (Shields 1936) from knowledge of the local friction velocity.

The critical shear stress $\tau_{\mathrm{c} 21}$ for a particle of diameter $d_{2}$ resting on a bed of particles of diameter $d_{1}$ can be written in terms of $\tau_{\mathrm{c} 1}$ for a particle of diameter $d_{1}$ resting on particles of same size $d_{1}$ (Julien 1998):

$$
\frac{\tau_{\mathrm{c} 21}}{\tau_{\mathrm{c} 1}}=\frac{d_{2}}{d_{1}} \sqrt{\frac{2}{\left(1+d_{2} / d_{1}\right)^{2}-2}}
$$


A sediment grain on a sloping river bank is less stable than one on the bed because the gravity force tends to move it downward (Ikeda 1982). According to Lane (1955), the ratio of the critical shear stress $\tau_{\mathrm{wc}}$ for a particle on a bank to that for the same particle on the bed $\tau_{\mathrm{c}}$ is

$$
\frac{\tau_{\mathrm{wc}}}{\tau_{\mathrm{c}}}=\cos \theta_{1} \sqrt{\left(1-\frac{\tan \theta_{1}}{\tan \phi}\right)^{2}}
$$

where $\theta_{1}$ is the slope of the bank and $\phi$ is the angle of repose for the sediment. The angle of repose of a particle can be found in Lane (1955) once the particle size is known.

Based on stream-bed tests conducted in several streams of Nebraska, Iowa and Mississippi, Hanson and Simon (2001) showed that $K$ can be estimated as a function of the critical shear stress as:

$$
K=10^{-7} \tau_{\mathrm{c}}^{-0.5}
$$

In this equation the erodibility coefficient in $\mathrm{m}^{3} \mathrm{~N}^{-1} \mathrm{~s}^{-1}$ is found by substituting the value of the critical shear stress in $\mathrm{Pa}$.

\section{Results and Discussion}

\subsection{Test Problem: Flow Near Groyne-Like Structures}

The performance of the 2D (depth-averaged) and 3D models were first checked against the experimental data of Rajaratnam and Nwachukwu (1983). In these experiments, a straight rectangular flume with smooth bed and sides was used to quantify the behaviour of the turbulent flow which occurs near groyne-like structures. The flume was $0.915 \mathrm{~m}$ wide and $0.189 \mathrm{~m}$ deep with a uniform inlet velocity, $U_{0}=0.25 \mathrm{~m} / \mathrm{s}$. The groyne used was an aluminum plate of thickness of $3 \mathrm{~mm}$ and length, $b=0.15 \mathrm{~m}$. Details of the experiment can be found in Rajaratnam and Nwachukwu (1983). The results of the same experiment were also used by Tingsanchalli and Maheswaran (1990), Molls and Chaudhry (1995) and Molinas and Hafez (2000) to verify their predictions. Tingsanchalli and Maheswaran (1990) used a depth-averaged flow model and the $k-\varepsilon$ turbulence model to compute the velocity and bottom shear stresses in the vicinity of the groyne. They also attempted to quantify experimental errors inherent in the experiments of Rajaratnam and Nwachukwu (1983) and reported the possible error to be about $7 \%$ for the mean velocity and $6 \%$ for the shear stress measurements. Molls and Chaudhry (1995) presented a mathematical model to solve the unsteady, depth-averaged equations with the turbulent stresses obtained from Boussinesq's eddy-viscosity concept. Molinas and Hafez (2000), on the other hand, used a 2D finite element model to determine the velocities and the turning angles around vertical wall abutments. The eddy viscosity in that study was determined by using the depth-averaged turbulent viscosity formulation of Rastogi and Rodi (1978).

The boundary conditions for the test problem were similar to those described in Section 2.1 except that a uniform velocity profile at the inlet boundary was used. In order to obtain uniform inlet and outlet flow conditions, these boundaries are required to be located sufficiently far away from the groyne so as not to influence the flow behavior there. Thangam and Speziale (1992), in a study of the related 
problem of flow over a two-dimensional backward-facing step, found that the inlet boundary must be at least five times the step height upstream of the step and the outlet boundary must be at least 30 times the step height downstream of the step. In the present computations, the inlet and outlet planes are placed at, respectively, 15 and 45 groyne lengths away from it.

The 2D computations were performed on three different grids having a total of $10,084,22,084$ and 48,484 computational nodes. The 3D computations, on the other hand, were performed using 121,008, 265,008 and 581,808 computational nodes. In the $2 \mathrm{D}$ computations, only one cell was used in the $z$-direction (i.e. the depth) while, in the $3 \mathrm{D}$ computations a total of 12 cells were used to resolve this coordinate. A schematic representations of the test problem and grid showing details around the groyne are depicted in Fig. $2 \mathrm{a}$ and $\mathrm{b}$. The flow is in the $x$ direction with $x=0$ defining the upstream side of the groyne, and $y=0$ is located at the bank with the groyne.

The resultant velocity is defined as $V_{x y}=\sqrt{U^{2}+V^{2}}$, where $U$ and $V$ are the depth-averaged velocities in the $x$ and $y$ directions, respectively. $U$ and $V$ are averaged in depthwise direction in the $3 \mathrm{D}$ model in order to obtain values for the resultant velocity that can be compared with the experimental data. Non-dimensional resultant velocity is obtained by dividing $V_{x y}$ by the uniform inlet velocity, $U_{0}$. Profiles of $V_{x y} / U_{0}$, computed in the $2 \mathrm{D}$ and $3 \mathrm{D}$ models, are plotted against $x / b$ for $y / b=1,1.5,2,3$ and 4 in Figs. 3 and 4, respectively. Upstream of the groyne, the predictions of $V_{x y} / U_{0}$ are very similar for all of the grids both in the $2 \mathrm{D}$ and $3 \mathrm{D}$ computations. However, some differences are observed downstream of the groyne where the flow is highly disturbed and the secondary velocities become significant. At $y / b=1,1.5$, and 3 , the 2D and 3D predictions compare well with the experiment. On the other hand, the $3 \mathrm{D}$ predictions are better at $y / b=3$ and 4 .

In the $2 \mathrm{D}$ computations, the bed shear stress $\tau_{\mathrm{b}}$ was obtained from the DarcyWeisbach formula incorporating an explicit form of the Colebrook-White equation with $\tau_{\mathrm{b}}=C_{f} \rho V_{x y}^{2}$. The resultant velocity was determined using the results of the finest grid while the friction coefficient $C_{f}$ was evaluated in a number of different

(a)

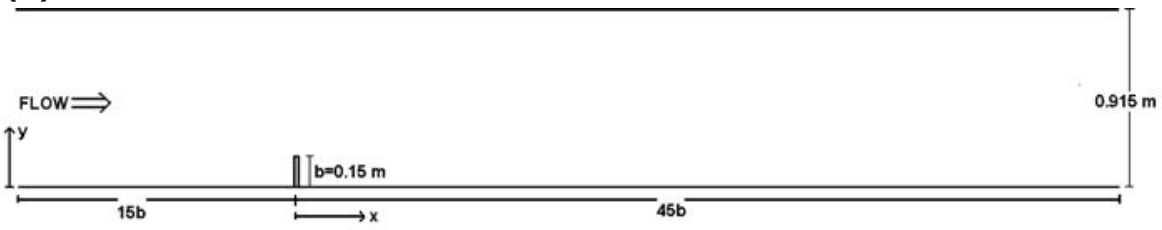

(b)

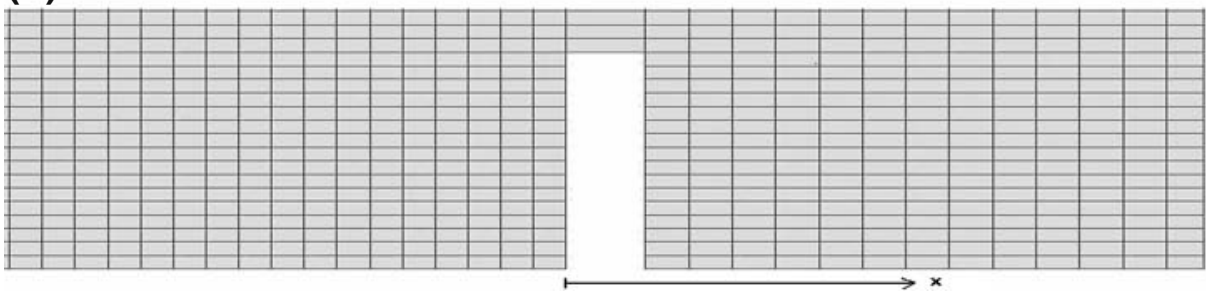

Fig. 2 a Planview of the test problem, b Planview of the grid zoomed around groyne 

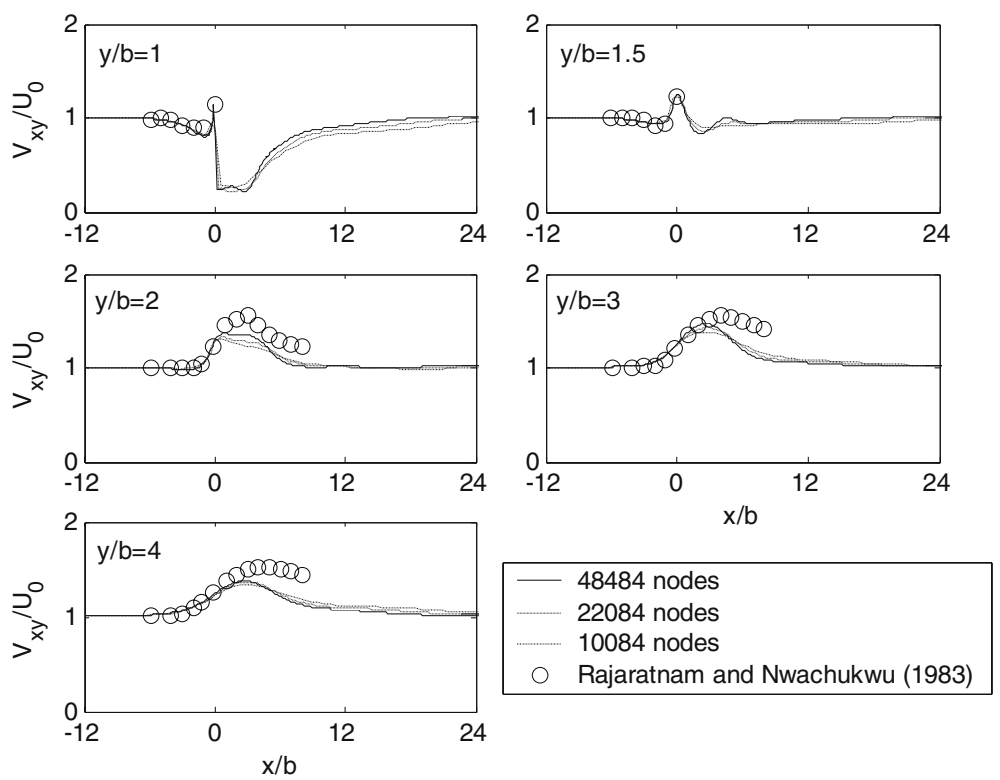

Fig. 3 Predicted (2D) and measured resultant velocity showing grid effects

ways in order to assess the sensitivity of this parameter to the choice of experimental correlation used. These approaches were:

1. Based on a depth-averaged velocity $V_{x y}$ obtained by assuming a logarithmic variation of the horizontal velocities with depth (Pierce and Zimmerman 1973).

2. Calculated by Pierce and Zimmerman (1973) using a correction for the 3D effects suggested by Johnston (1960). Here, the turning angle between the limiting bottom streamline and the main flow direction was assumed to be twice that between the main flow and upstream approaching direction (Tingsanchalli and Maheswaran 1990).

3. By using Chezy's equation to be valid and by taking Chezy's constant to be $118 \mathrm{~m}^{1 / 2} / \mathrm{s}$.

4. By using Darcy-Weisbach formula incorporating an explicit form of the Colebrook-White equation.

The predicted shear-stress distributions using these four alternative approaches are presented in Fig. 5. From this figure it is clear that the approach suggested by Pierce and Zimmerman (1973) and Colebrook-White equation (plotted as CW) obtain nearly identical shear stress values. The method of Pierce and Zimmerman (1973), modified using the proposals of Johnston (1960), gives better predictions near groyne where the 3D effects are quite strong. Moreover, the predictions for the bed shear obtained with Chezy's equation are approximately half the values obtained with the other formulae considered. More realistic values of Chezy constant can be found by computer optimization but this was not pursued here.

Figure 6 depicts the angles of the velocity vectors with respect to the streamwise direction at the nose of the groyne as obtained by both the 2D and $3 \mathrm{D}$ computations. 

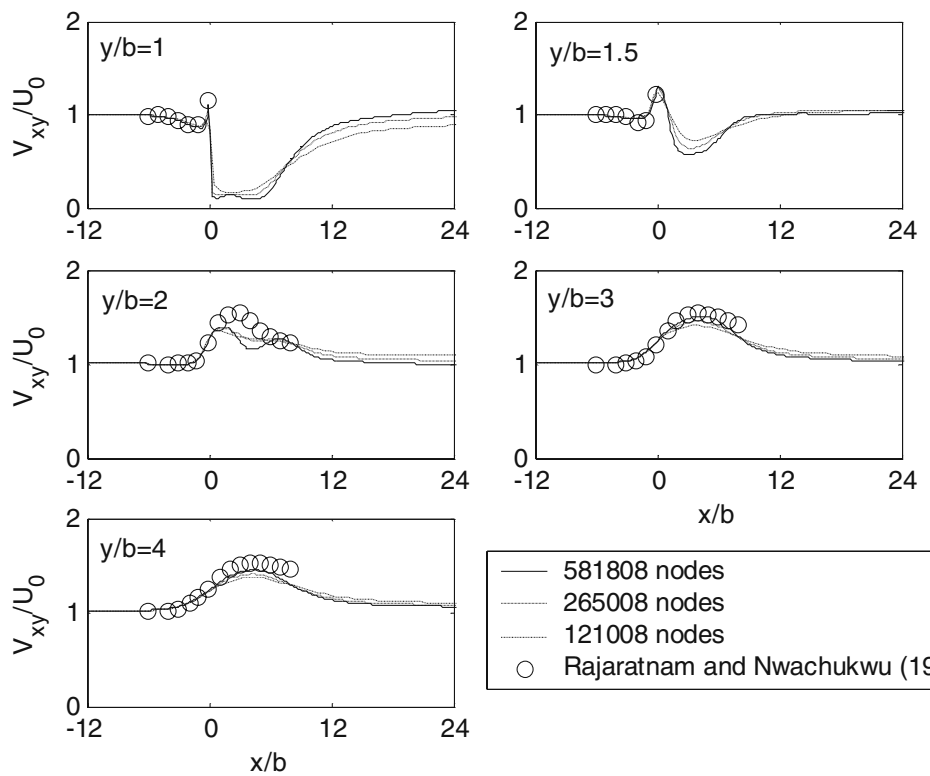

$\mathrm{x} / \mathrm{b}$

581808 nodes

265008 nodes

121008 nodes

- Rajaratnam and Nwachukwu (1983)

Fig. 4 Predicted (3D) and measured resultant velocity showing grid effects

The angles are plotted for twelve nodes from the channel bed to the water surface for the 3D computation. Node number one refers to the node nearest to bed where the skewness of the velocity vector amounts to $75.9^{\circ}$, which is the maximum value attained by this parameter. The angle calculated by the $2 \mathrm{D}$ approach is only $55.6^{\circ}$ : this more modest skewness is obtained in the 3D computations at the fifthnode away from the bed. Compared with the 2D results, the average of the angles at the 12 nodes was $8 \%$ larger in the $3 \mathrm{D}$ computations. This represents a strong dependence of flow skewness on depth which is characteristic of fully-developed three-dimensional turbulent boundary layers.

To conclude, both the 2D and the 3D computations were found to yield adequate results for this test flow with the depth-averaged velocities predicted with similar degree of accuracy using either approach. The obvious advantage of the 3D computations is that the computed results yield a description of the variation of dependent variables in depthwise direction though, in practice, such description is important in only a few cases such as, for example, buoyancy-driven flows. On the other hand, the 2D computations are significantly less demanding of computational resources.

\subsection{Computations for a Reach of the Sacramento River with Groynes}

The particular reach of the Sacramento River under consideration is located about 60 miles north of the City of Sacramento, CA. Our interest is primarily focused on the right bank of this reach, just upstream of a bridge, where extensive bank erosion has been observed. Flora (2003) and Mishra and Lindsey (2000) provide a history of the bank erosion at this location. Briefly, bridge inspection carried out in 1952 revealed that a $40 \mathrm{~m}$ section of the right bank had retreated by about $7 \mathrm{~m}$ relative 

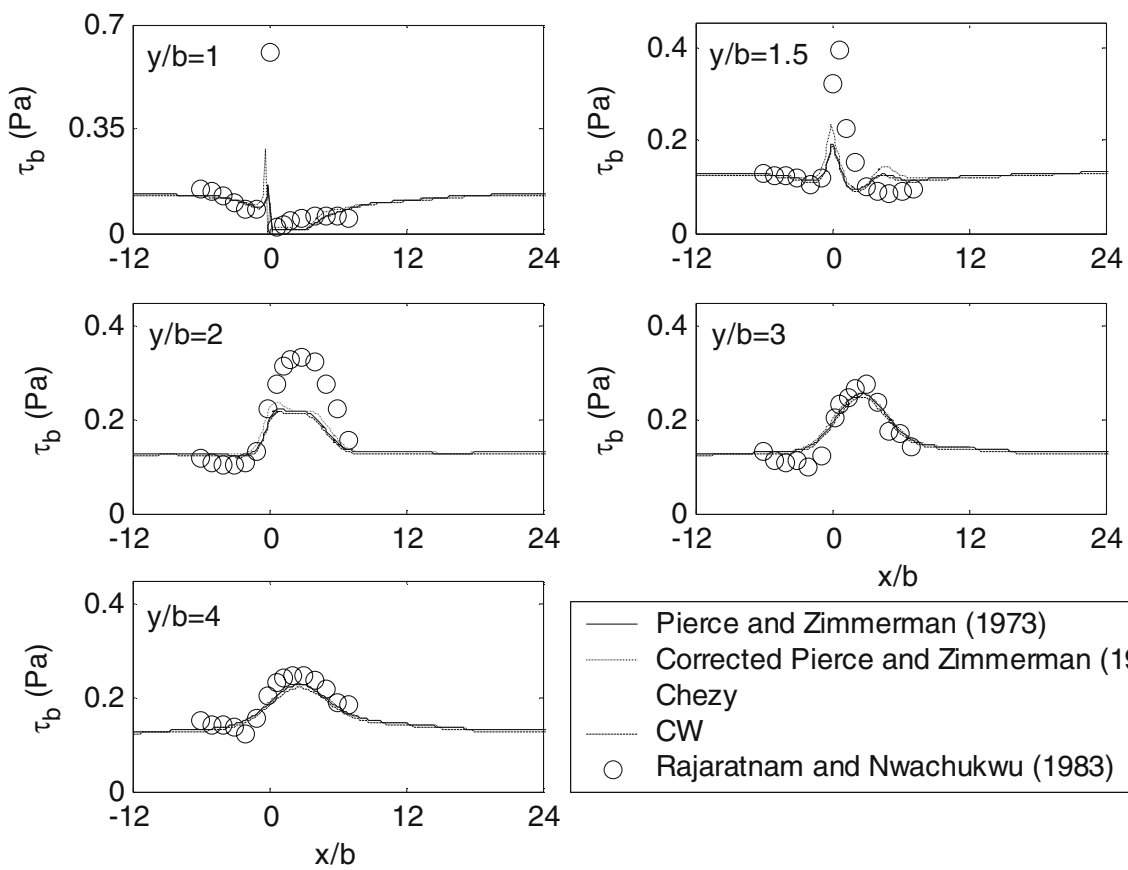

Pierce and Zimmerman (1973)

Corrected Pierce and Zimmerman (1973) Chezy

CW

Rajaratnam and Nwachukwu (1983)

Fig. 5 Predicted (2D) and measured bed shear stress using different formulae

to a previous survey. Continued erosion was noted in a survey conducted in 1963 , and, in 1970, it was noted that an additional 9 to $15 \mathrm{~m}$ of erosion had occurred and threatened the bridge integrity. Floods in 1996 and 1997 eroded about $6 \mathrm{~m}$ in the right bank. In 1997, a sheet pile containment structure was constructed around the pier at the right bank. After 1997, continued bank erosion lead authorities to consider other solutions. A physical model study for the river reach under consideration (see Fig. 7) was performed at the Hydraulics Laboratory at the University of California, Davis. The outcome of that study was a recommendation to deploy four groynes to deflect

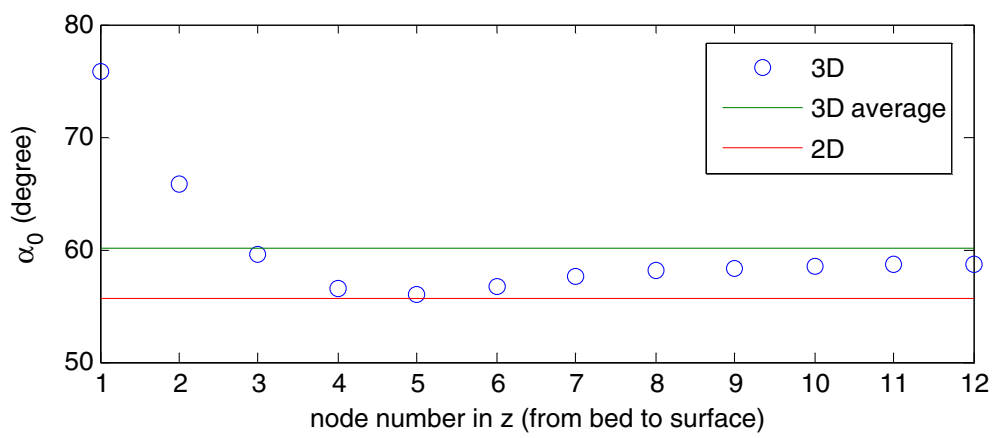

Fig. 6 Skewness of velocity vectors relative to streamwise direction at the nose of the groyne in 2D and $3 \mathrm{D}$ computations 


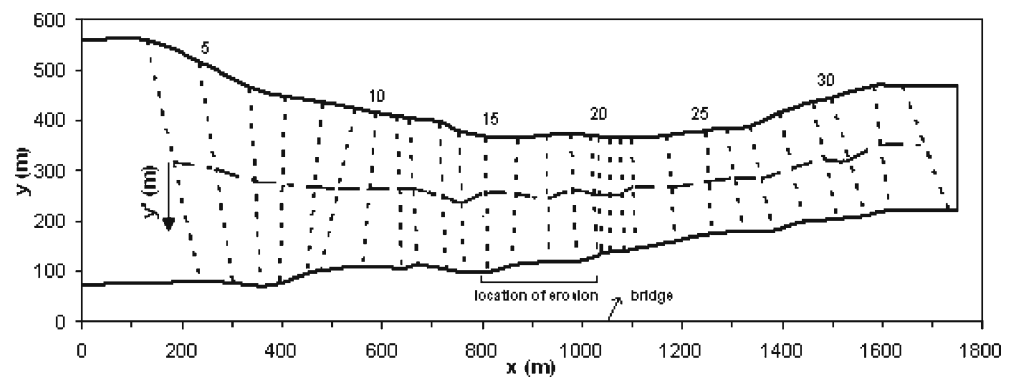

Fig. 7 Location and orientation of field survey transects in river scale. Dashed line is the line connecting centerlines of transects. $y^{\prime}$ for each transect is distance in meters from the centerline. Numbers at top are transect numbers

fast-moving flow away from the eroding bank. This recommendation was arrived at from a combination of flow-velocity measurements with a miniature propeller meter, and from flow visualization using both floating particles and dissolved dye. Following the recommendations of this study, the four groynes were constructed in 2004 and these have so far been successful in producing the required bank stabilization. The physical-model study also revealed that the same groynes, while providing protection to the river bank upstream of the bridge, will lead to bank erosion immediately downstream of it due to the strengthening of an existing vortex that forms downstream of the bridge abutment. Subsequent field observations have confirmed this finding. In what follows, we describe the computations that were carried out in support of the physical-model study.

A plan view of the reach of interest is presented in Fig. 8 which also defines the coordinates system used. A schematic view of the 2D and 3D computation domains are shown at Figs. 7 and 9. The inlet plane is located at $x=0$. Cubic splines were utilized for the construction of the computational grid. As pointed out in Ercan and Younis (2008), the number and location of the survey points used to construct the channel cross sections can profoundly affect the quality of the grid. In some cases, the survey data are sparse leading to the generation of cross-sectional profiles that differ in essential detail from the real ones. In other cases, the number and distribution of the survey data are such that unrealistic surface discontinuities are produced. Such

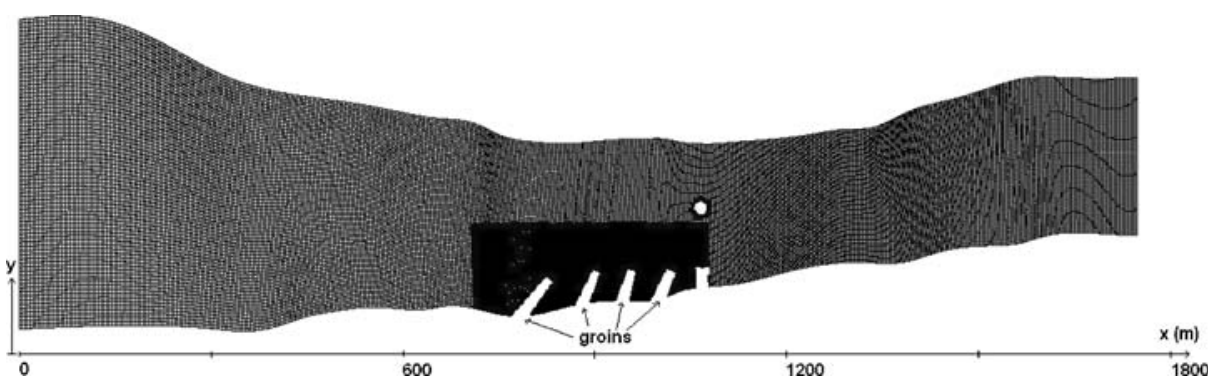

Fig. $8 x-y$ plane schematic of 2D and 3D computations for the reach of the Sacramento River with four groynes 


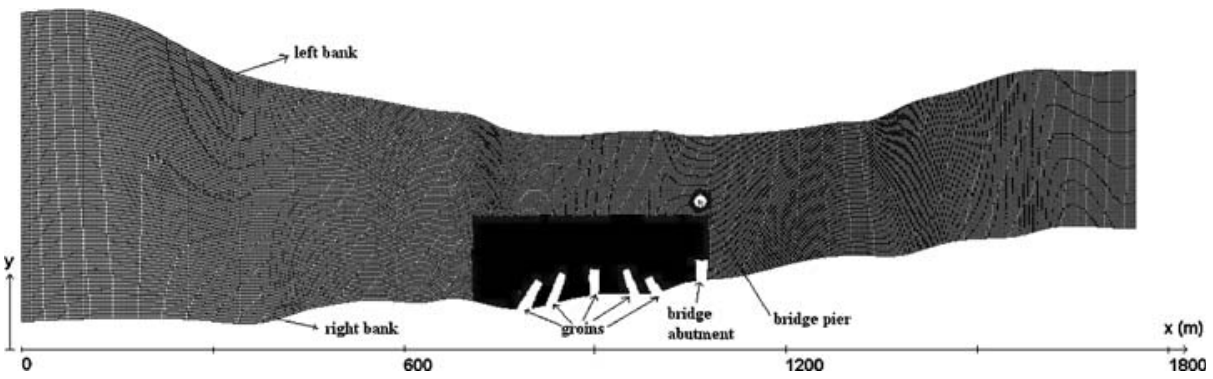

Fig. $9 x-y$ plane schematic of 2D and 3D computations for the reach of the Sacramento River with five groynes

discontinuities are known to slow down the convergence of an iterative solution procedure and, in some instances, produce instabilities that can cause the iterative process to diverge. A detailed discussion of the procedure for grid generation for complex river geometries, and the impact of the grid on the quality of the computed results can be found in Ercan and Younis (2008).

The estimated 100-year flood discharge at this location of the Sacramento River is about $7,000 \mathrm{~m}^{3} / \mathrm{s}$. The computational and physical-model studies reported here are based on the Sacramento River flow rate of $4,049 \mathrm{~m}^{3} / \mathrm{s}$, which is approximately the design discharge for an 8-year return period.

The 2D computations with five groynes were performed using three different grids having a total of 24,064; 36,103 and 48,131 computational nodes. The 3D computations were performed using 240,638; 336,888 and 385,080 computational nodes. In both cases, the grid nodes were non-uniformly distributed in order to better resolve the regions of the flow that most strongly influence bank erosion (Figs. 8 and 9). The results of computations obtained on different grids were used to quantify the discretization errors which, in this study, was done using the Grid Convergence Index (GCI) method. This method is based on Richardson extrapolation and was first proposed by Roache $(1994,1997)$. Briefly, the method entails the determination of an index which reflects the uncertainty present in a numerical solution obtained with a particular grid. This estimate is based on comparisons with the solutions obtained with two other grids. Further details of this method, together with a demonstration of its utility in open channel flows, may be found in Hardy et al. (2003). Figure 10a-d present the results for section $15(x=808 \mathrm{~m})$. The streamwise velocity in the $2 \mathrm{D}$ model and the streamwise velocity at the surface in the 3D model are given in Fig. 10a and c. Figure 10b shows the GCI at section 15 for the finest grid of the $2 \mathrm{D}$ computations. The average GCI using 38 data points is $3.6 \%$. The largest value of the GCI is obtained near the right bank where it amounts to $27.7 \%$. Oscillatory convergence (which is indicative of regions of the flow where the GCI method becomes inapplicable) occurs at $21 \%$ of the total data points. An alternative method for discretization error analysis is the so-called Power Law Method (Celik and Karatekin 1997) and its application in this flow yielded average and maximum relative error values of $3.3 \%$ and $13 \%$, respectively.

For the 3D results, the discretization errors calculated by the GCI and the Power Law methods at section 15 for the finest grid are shown at Fig. 10d. The errors calculated by the GCI Method at 31 data points with an average $0.7 \%$ and 

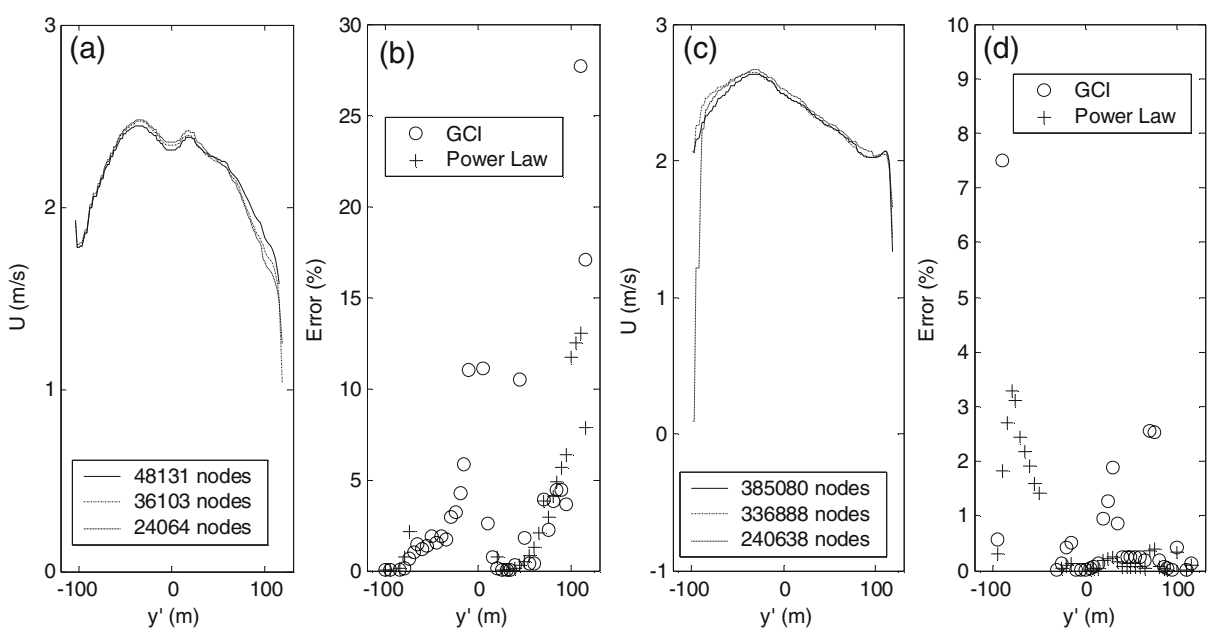

Fig. 10 a Streamwise velocity at Section 15 versus $y^{\prime}$ (as in Fig. 7) for different grids in 2D model with five groynes. b Error calculated by the GCI and the Power Law methods versus $y^{\prime}$ in 2D model with five groynes. $\mathbf{c}$ Streamwise surface velocity in $x$ direction at Section 15 versus $y^{\prime}$ for different grids in 3D model with five groynes. d Error calculated by the GCI and the Power Law methods versus $y^{\prime}$ in $3 \mathrm{D}$ model with five groynes

maximum $7.5 \%$. Oscillatory convergence occurs at $87 \%$ of the total data points. The discretization errors by Power Law Method are calculated at 34 data points with an average of $0.7 \%$ and a maximum of $3.3 \%$. These results are well within the accepted limits for 3D computations of flows in complex domains where it is impractical to maintain fine resolution throughout the flow domain due to the very large variation in the length scales involved (e.g. Lane et al. 2000).

The computed velocities obtained with the 2D and 3D models are next compared with experimental data. For this purpose, the velocities of sections 15, 16, 17, 18, 20, 24 and 25 are given in Fig. 11 and in Table 1 where they are presented against the distance from the river centerline. These sections are located at distances of 808 , $864,931,982,1035,1178$, and $1252 \mathrm{~m}$ from the inlet. The normalized root mean square errors for the $2 \mathrm{D}$ and $3 \mathrm{D}$ computations are 0.160 and 0.166 , respectively. As the error values associated with the $2 \mathrm{D}$ and the $3 \mathrm{D}$ calculations are close, and as the uncertainties in both experiments and computations are unknown, it is difficult to rank the $2 \mathrm{D}$ and the $3 \mathrm{D}$ models according to a definite measure of accuracy. Nevertheless, it should be noted that the depth-averaged velocities are predicted to the same degree of accuracy with both approaches. Therefore, if the purpose of the computations is merely to obtain a general impression of the flow as represented by depth-averaged values then the use of a depth-average model would be quite sufficient. This conclusion is consistent with that arrived at in Ercan and Younis (2008) from their 2D and 3D computations for the same reach with no groynes. Although depth averaged velocities are predicted with similar degree of accuracy using 2D and 3D models, 2D models do not provide depth wise variation of velocity. Depth averaged velocity predicted by $2 \mathrm{D}$ model and velocity at the surface predicted by $3 \mathrm{D}$ model are discussed next; unlike $2 \mathrm{D}$ model 3D model shows flow reversal upstream of the bridge at the left and right banks. 


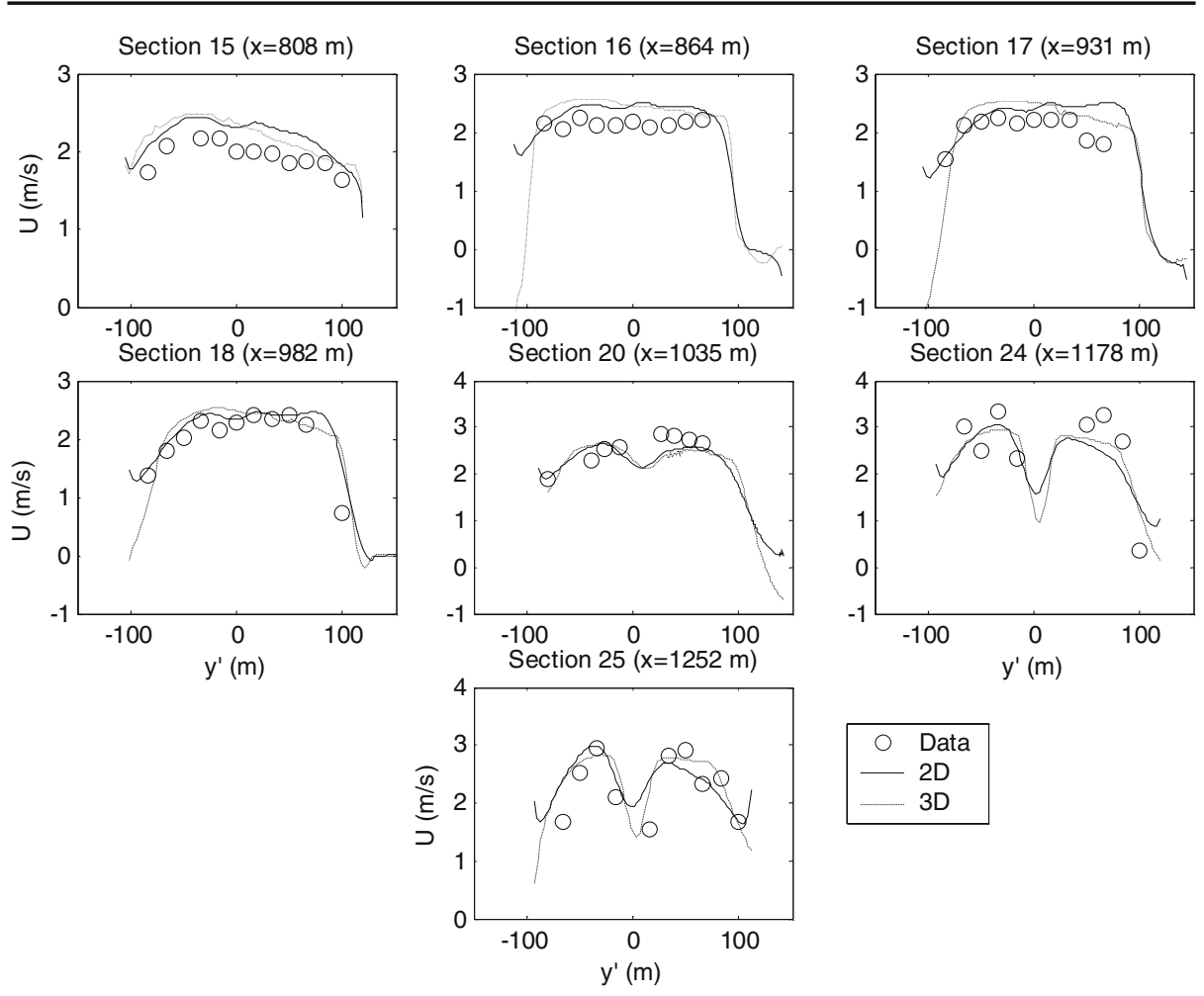

Fig. 11 Streamwise velocity versus $y^{\prime}$ for $2 \mathrm{D}$ and $3 \mathrm{D}$ computations for the reach of the Sacramento River with five groynes. The data refer to velocities obtained in the physical-model

Contours of the velocity predicted with the 2D model are shown as in Fig. 12. The velocity vectors in the region $600 \mathrm{~m}<x<1,300 \mathrm{~m}$ obtained with the $2 \mathrm{D}$ model are plotted in Fig. 13. The 3D model results for the surface velocity magnitudes and for the velocity vectors in the same region are presented in Figs. 14 and 15. Figures 12 and 14 suggest that the velocity magnitudes predicted by the $2 \mathrm{D}$ model are close to the ones predicted at the surface by $3 \mathrm{D}$ model. Both the $2 \mathrm{D}$ and $3 \mathrm{D}$ velocity computations show that a region of reversed flow develops downstream of the abutment at the right bank and the circular bridge pier in the main channel. Relatively smaller recirculation zones are predicted to occur between the groynes. The computations also show that the groynes reduce the cross-sectional flow area where they are located and thus cause the flow to accelerate in the main channel. The most striking impact of the groynes is seen in the flow velocity near the right bank, upstream of the abutment which is quite high for the no-groyne case but which is reduced considerably by the placement of the groynes. According to Fig. 15, flow reversal is observed in the region $730 \mathrm{~m}<x<810 \mathrm{~m}$ at the surface of the nearbank region of the $3 \mathrm{D}$ model. This flow reversal is limited to the near-bank zone for the no-groynes case of 3D model, and is not observed for the no-groyne case of 2D model. Inspection of the surface velocity vectors between the upstream groynes for the five-groyne and the four-groyne cases in the $3 \mathrm{D}$ computations reveal the presence of strong recirculation zones between the groynes and away from the bank. The 
Table 1 Streamwise velocity versus $y^{\prime}$ for 2D and 3D computations for the reach of the Sacramento River with five groynes

\begin{tabular}{|c|c|c|c|c|c|c|c|c|c|c|c|}
\hline \multicolumn{12}{|c|}{ Section $15(x=808 \mathrm{~m})$} \\
\hline$Y^{\prime}(\mathrm{m})$ & -82.71 & -66.17 & -33.09 & -16.54 & 0.00 & 16.54 & 33.09 & 49.63 & 66.17 & 82.71 & 99.26 \\
\hline Data & 1.73 & 2.08 & 2.17 & 2.17 & 2.00 & 2.00 & 1.97 & 1.85 & 1.88 & 1.84 & 1.63 \\
\hline 2D & 2.06 & 2.26 & 2.44 & 2.37 & 2.31 & 2.38 & 2.31 & 2.25 & 2.17 & 2.01 & 1.82 \\
\hline $3 \mathrm{D}$ & 2.21 & 2.36 & 2.49 & 2.41 & 2.36 & 2.28 & 2.17 & 2.09 & 2.01 & 1.90 & 1.81 \\
\hline \multicolumn{12}{|c|}{ Section $16(x=864 \mathrm{~m})$} \\
\hline$y^{\prime}(\mathrm{m})$ & -82.71 & -66.17 & -49.63 & -33.09 & -16.54 & 0.00 & 16.54 & 33.09 & 49.63 & 66.17 & \\
\hline Data & 2.15 & 2.06 & 2.23 & 2.12 & 2.12 & 2.18 & 2.08 & 2.10 & 2.18 & 2.20 & \\
\hline 2D & 2.08 & 2.31 & 2.45 & 2.47 & 2.39 & 2.47 & 2.48 & 2.43 & 2.44 & 2.36 & \\
\hline $3 \mathrm{D}$ & 2.33 & 2.50 & 2.57 & 2.58 & 2.51 & 2.45 & 2.42 & 2.38 & 2.35 & 2.28 & \\
\hline \multicolumn{12}{|c|}{ Section $17(x=931 \mathrm{~m})$} \\
\hline$y^{\prime}(\mathrm{m})$ & -82.71 & -66.17 & -49.63 & -33.09 & -16.54 & 0.00 & 16.54 & 33.09 & 49.63 & 66.17 & \\
\hline Data & 1.54 & 2.10 & 2.17 & 2.23 & 2.15 & 2.20 & 2.21 & 2.21 & 1.87 & 1.78 & \\
\hline 2D & 1.59 & 1.97 & 2.25 & 2.40 & 2.38 & 2.38 & 2.51 & 2.42 & 2.45 & 2.49 & \\
\hline $3 \mathrm{D}$ & 0.89 & 2.26 & 2.46 & 2.53 & 2.54 & 2.50 & 2.48 & 2.30 & 2.27 & 2.18 & \\
\hline \multicolumn{12}{|c|}{ Section $18(x=982 \mathrm{~m})$} \\
\hline$Y^{\prime}(\mathrm{m})$ & -82.55 & -66.04 & -49.53 & -33.02 & -16.51 & 0.00 & 16.51 & 33.02 & 49.53 & 66.04 & 99.06 \\
\hline Data & 1.37 & 1.78 & 2.01 & 2.30 & 2.16 & 2.27 & 2.40 & 2.35 & 2.39 & 2.25 & 0.71 \\
\hline $2 \mathrm{D}$ & 1.50 & 1.90 & 2.22 & 2.40 & 2.40 & 2.33 & 2.45 & 2.41 & 2.39 & 2.44 & 1.62 \\
\hline $3 \mathrm{D}$ & 0.98 & 2.02 & 2.35 & 2.48 & 2.53 & 2.47 & 2.43 & 2.41 & 2.32 & 2.23 & 1.84 \\
\hline \multicolumn{12}{|c|}{ Section $20(x=1,035 \mathrm{~m})$} \\
\hline$y^{\prime}(\mathrm{m})$ & -79.40 & -39.70 & -26.47 & -13.23 & 26.47 & 39.70 & 52.94 & 66.17 & & & \\
\hline Data & 1.89 & 2.27 & 2.52 & 2.55 & 2.85 & 2.82 & 2.75 & 2.64 & & & \\
\hline $2 \mathrm{D}$ & 1.92 & 2.58 & 2.63 & 2.48 & 2.40 & 2.52 & 2.57 & 2.55 & & & \\
\hline $3 \mathrm{D}$ & 1.58 & 2.61 & 2.64 & 2.55 & 2.31 & 2.43 & 2.49 & 2.48 & & & \\
\hline \multicolumn{12}{|c|}{ Section $24(x=1,178 \mathrm{~m})$} \\
\hline$y^{\prime}(\mathrm{m})$ & -66.17 & -49.63 & -33.09 & -16.54 & 49.63 & 66.17 & 82.71 & 99.26 & & & \\
\hline Data & 3.01 & 2.50 & 3.32 & 2.32 & 3.04 & 3.26 & 2.70 & 0.34 & & & \\
\hline $2 \mathrm{D}$ & 2.55 & 2.91 & 3.05 & 2.60 & 2.64 & 2.43 & 2.05 & 1.30 & & & \\
\hline $3 \mathrm{D}$ & 2.62 & 2.86 & 2.94 & 2.84 & 2.76 & 2.65 & 2.37 & 1.23 & & & \\
\hline \multicolumn{12}{|c|}{ Section $25(x=1,252 \mathrm{~m})$} \\
\hline$y^{\prime}(\mathrm{m})$ & -66.17 & -49.63 & -33.09 & -16.54 & 16.54 & 33.09 & 49.63 & 66.17 & 82.71 & 99.26 & \\
\hline Data & 1.69 & 2.51 & 2.93 & 2.11 & 1.53 & 2.82 & 2.90 & 2.33 & 2.42 & 1.69 & \\
\hline 2D & 2.37 & 2.84 & 2.99 & 2.44 & 2.42 & 2.68 & 2.55 & 2.40 & 2.08 & 1.69 & \\
\hline $3 \mathrm{D}$ & 2.38 & 2.70 & 2.82 & 2.72 & 2.33 & 2.77 & 2.76 & 2.72 & 2.41 & 1.63 & \\
\hline
\end{tabular}

presence of these zones suggests that sedimentation will occur in the regions between the groynes leading, eventually, to rehabilitation of the eroded bank. Subsequent to the installation of the groynes in the river, it was indeed observed that sedimentation did occur in these zones, facilitated by the detention of large floating elements such as tree branches and other debris.

Figure 16 presents the predicted profiles of turbulence kinetic energy. This parameter is seen to increase downstream of the bridge pier in the main channel and downstream of the bridge abutment near the right bank. In general, high turbulence activity is observed in regions of high shear. Another zone of high turbulence activity is observed near the nose of the groyne. 


\section{(a)}

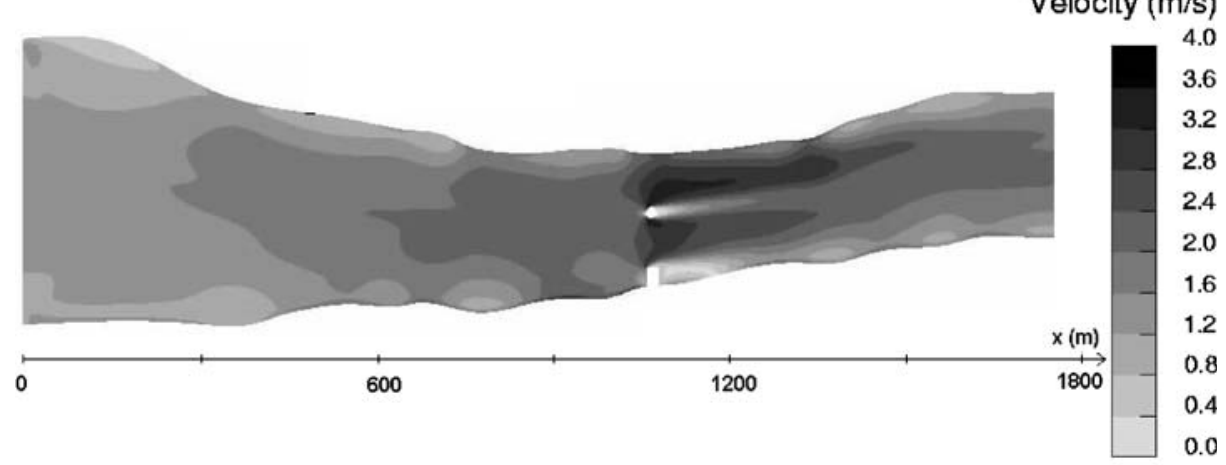

(b)

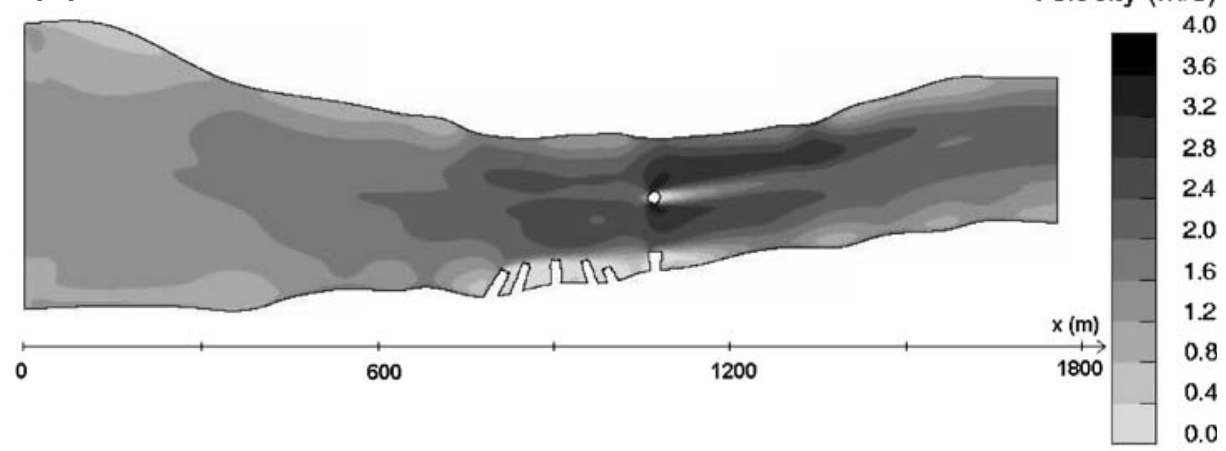

(c)

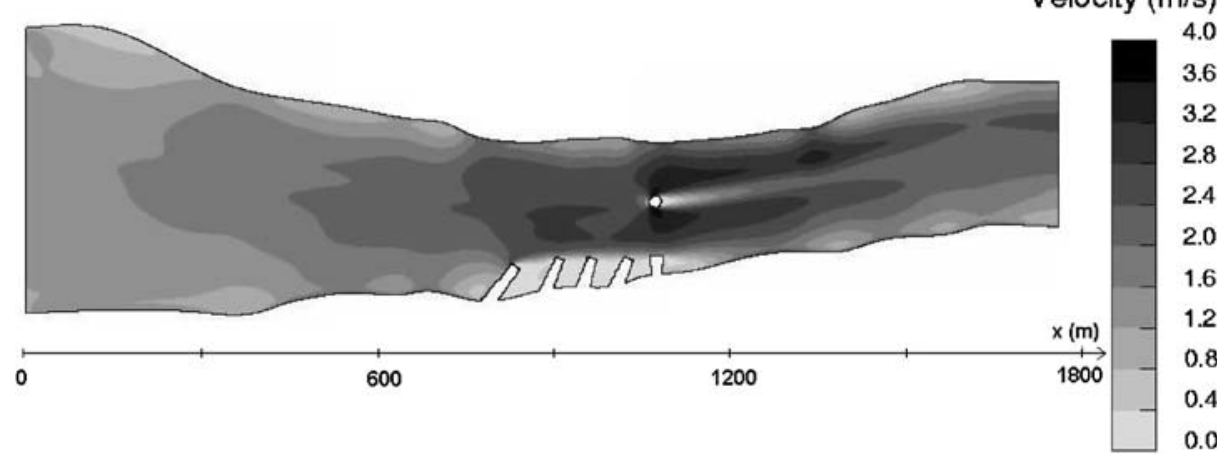

Fig. 12 Velocity magnitudes for a no groynes, $\mathbf{b}$ five-groynes and $\mathbf{c}$ four-groynes cases in 2D computations

The bed shear stress calculated by wall functions in the 3D model is plotted in Fig. 17. The shear stress, like the velocity magnitude, is quite high near the right bank upstream of the abutment $(x=900 \mathrm{~m})$. The placement of the groynes leads to reduction in the magnitude of the bank shear stress and an increase in the magnitude of this parameter in the main channel. 
(a)

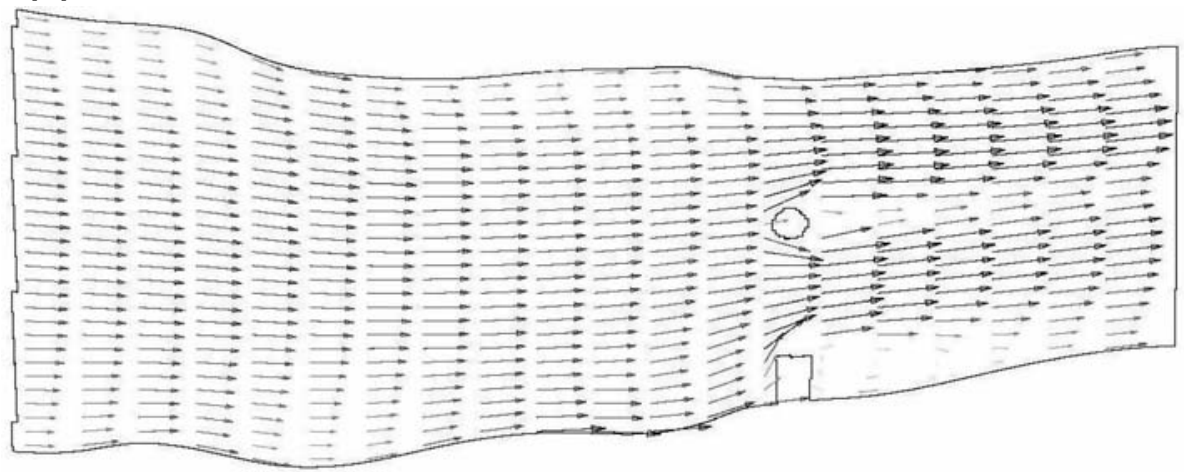

(b)

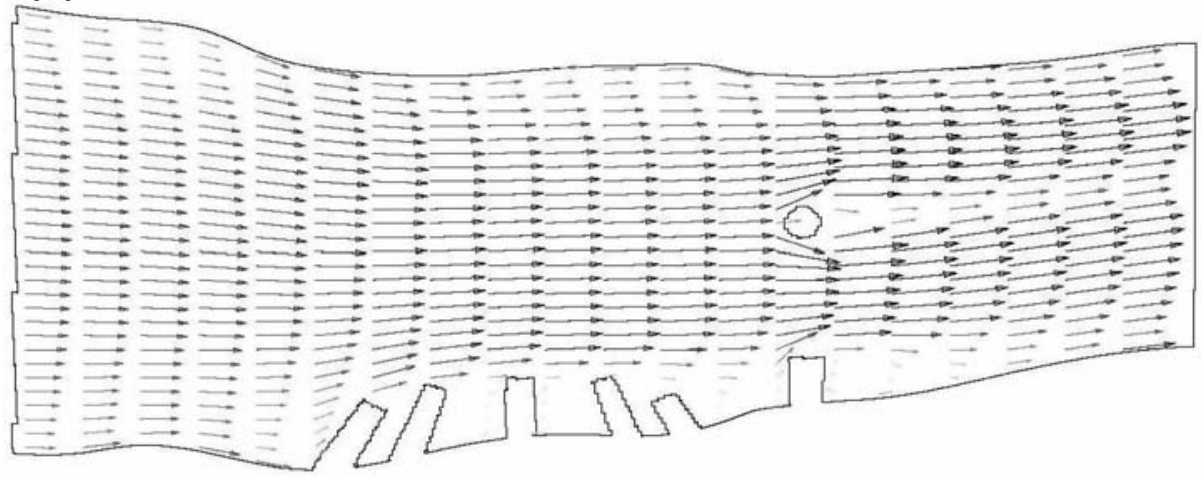

(c)

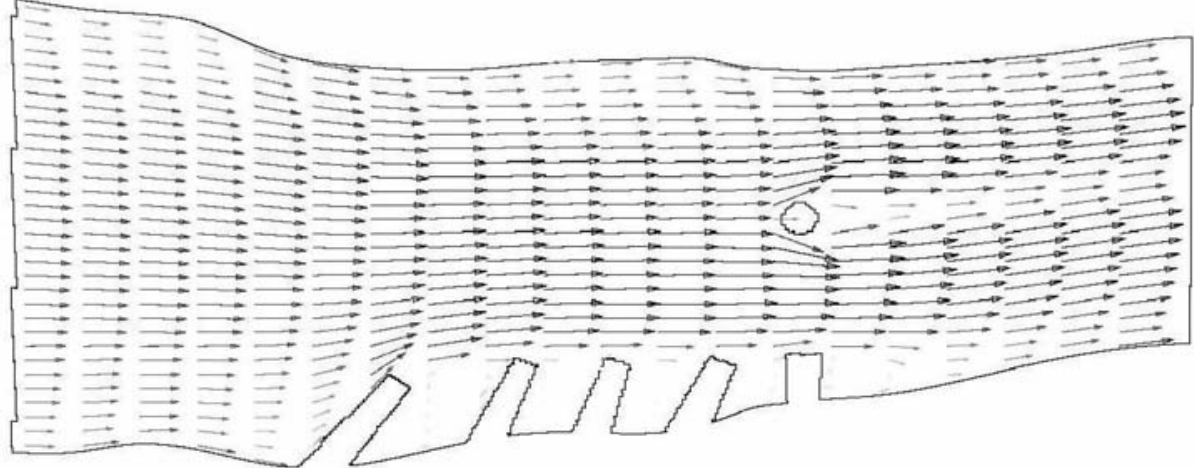

Fig. 13 Velocity vectors at $600 \mathrm{~m}<x<1,300 \mathrm{~m}$ for a no groynes, $\mathbf{b}$ five-groynes and $\mathbf{c}$ five-groynes cases in 2D computations

Estimation of bank erosion rates here is based on the excess shear stress near the bank as proposed by Partheniades (1965) in Eq. 11. Hanson and Simon (2001) relate the erodibility coefficient to the critical shear stress that appears in Eq. 11. The streamwise and spanwise shear stresses at the right bank for the no-groyne and 


\section{(a)}

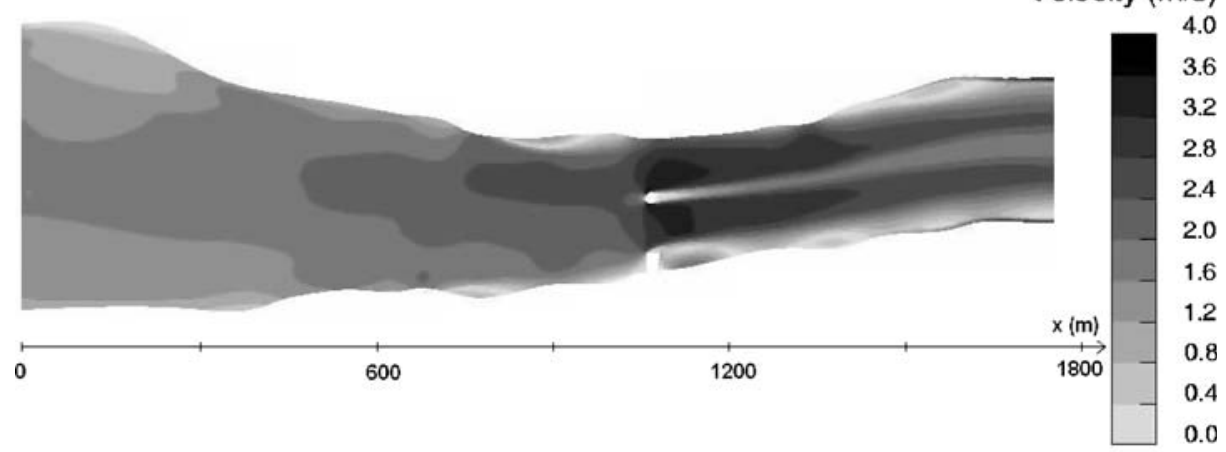

(b)

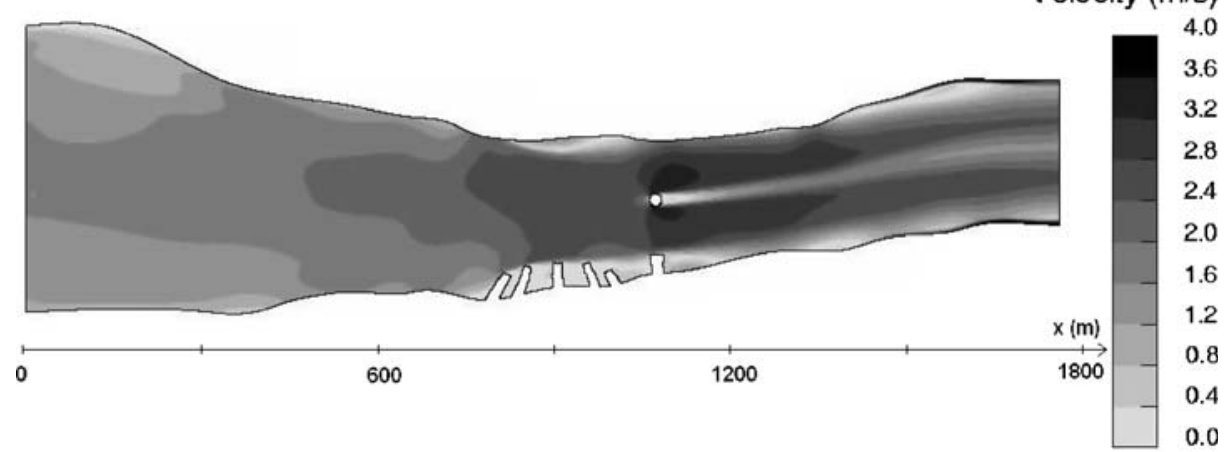

(c)

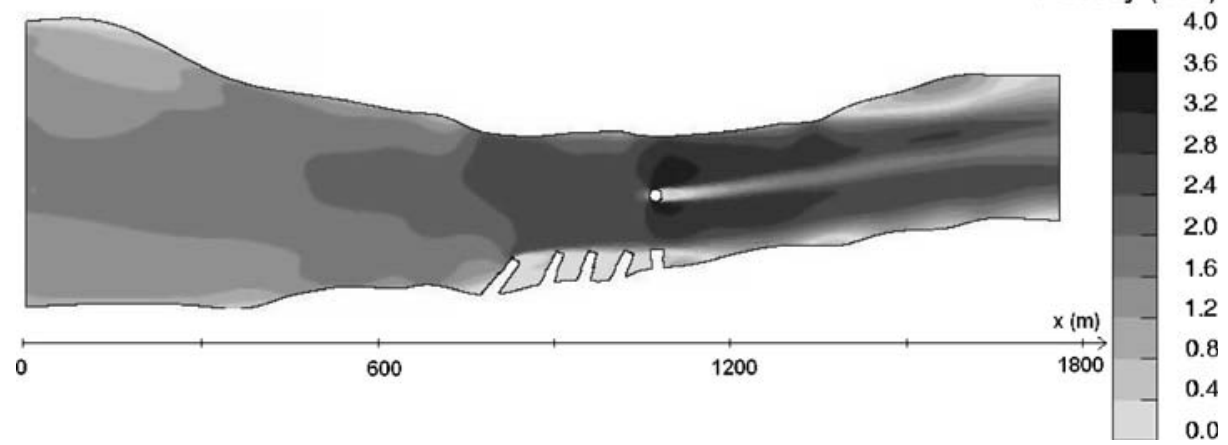

Fig. 14 Velocity magnitudes at the river surface for a no groynes, $\mathbf{b}$ five-groynes and $\mathbf{c}$ five-groynes cases in $3 \mathrm{D}$ computations

the four-groyne cases as calculated by the 3D computational model are presented in Fig. 18a, b. As can be seen, the groynes cause reduction in streamwise and spanwise shear stresses upstream of the bridge, where they are located, and increase the shear stress by a small amount downstream of the abutment. 
(a)

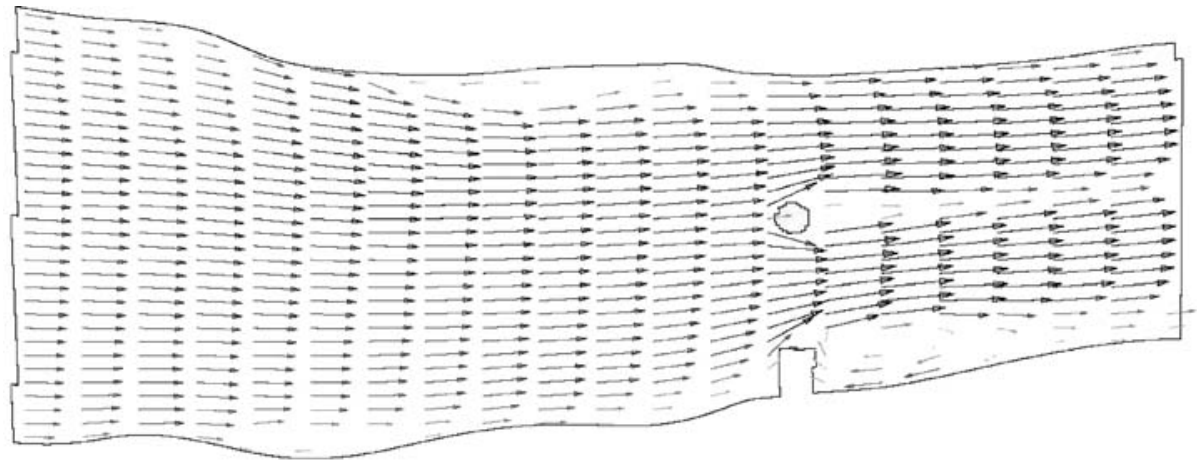

(b)

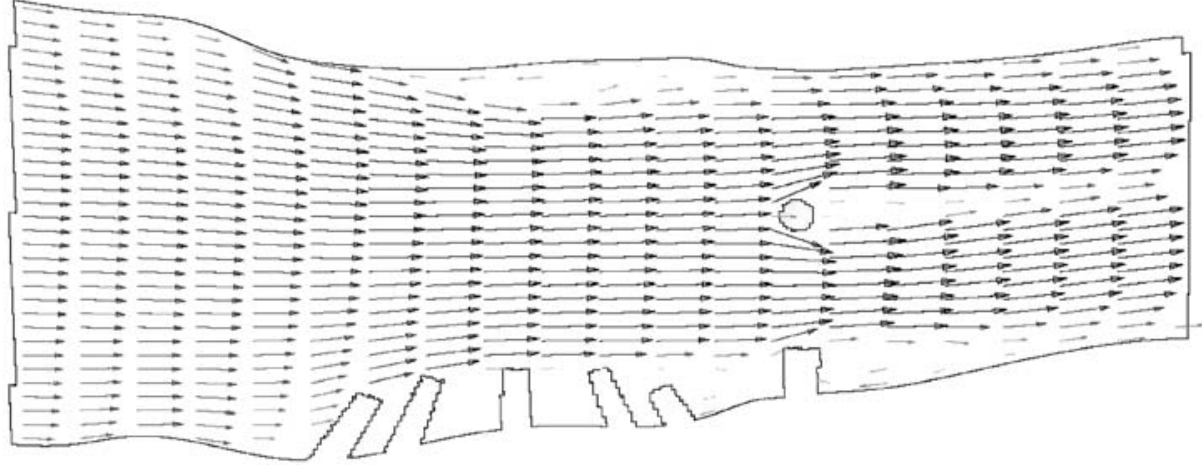

(c)

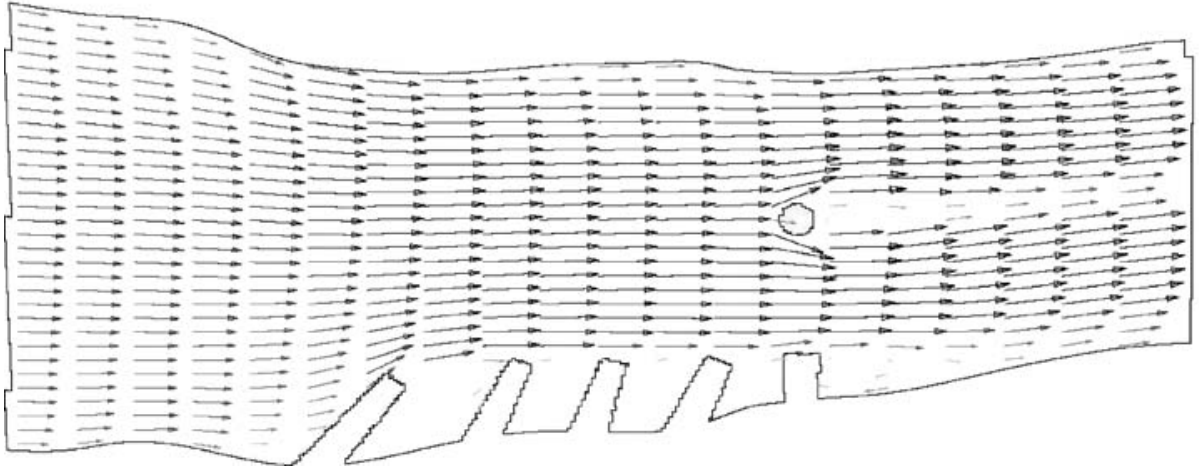

Fig. 15 Surface velocity vectors at $600 \mathrm{~m}<x<1,300 \mathrm{~m}$ for a no groynes, $\mathbf{b}$ five-groynes and $\mathbf{c}$ fourgroynes cases in $3 \mathrm{D}$ computations

The critical shear stress, which depends on the physical properties of the erodible material, was calculated here using the Shields curve (Shields 1936). Singer and Dunne (2001) reported that the bed of the Sacramento River at the reach under present consideration is composed of coarse, medium and fine sand layers overlain by lobes of fine and medium gravels. The critical shear stress of a particle of diameter 


\section{(a)}

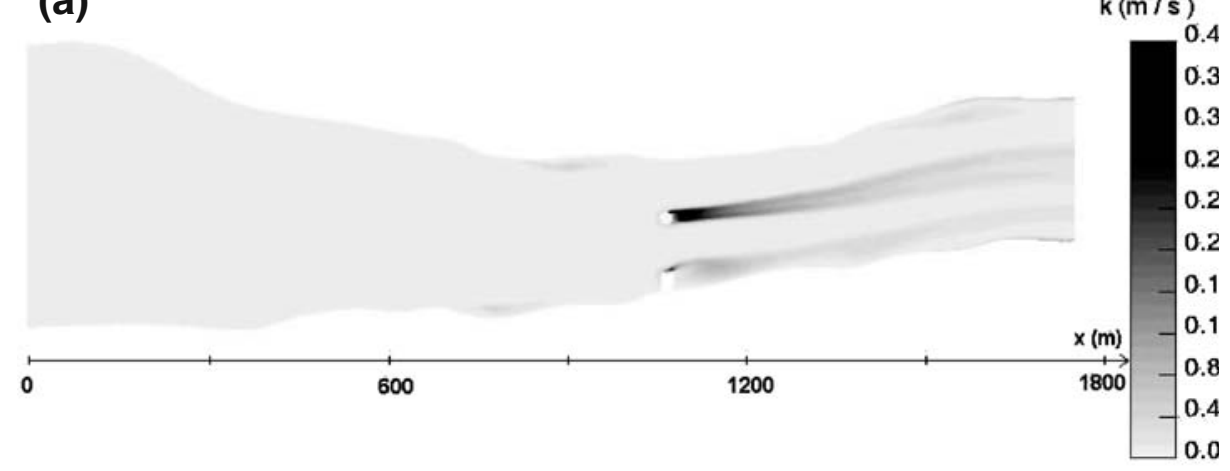

(b)

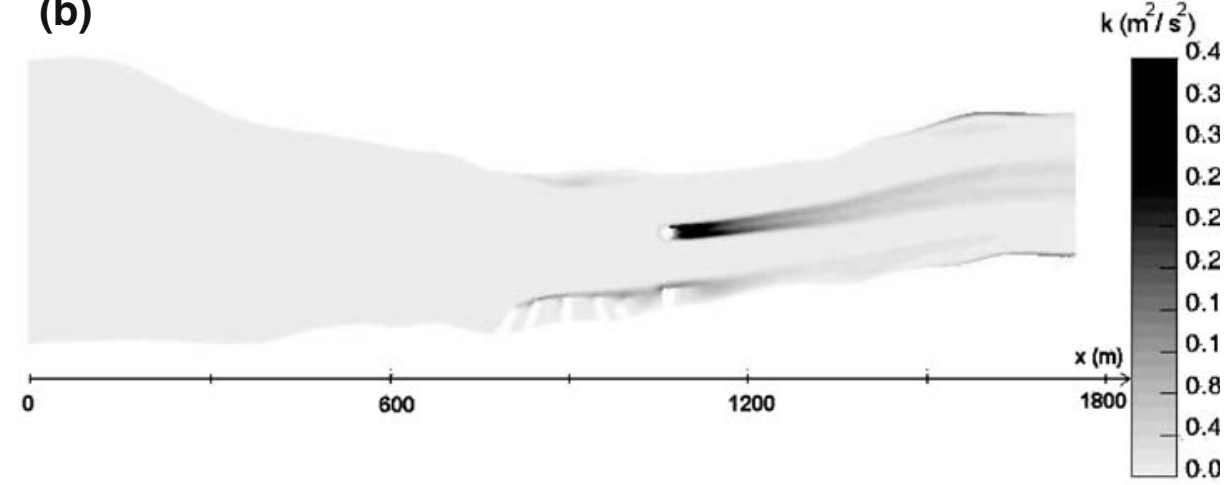

(c)

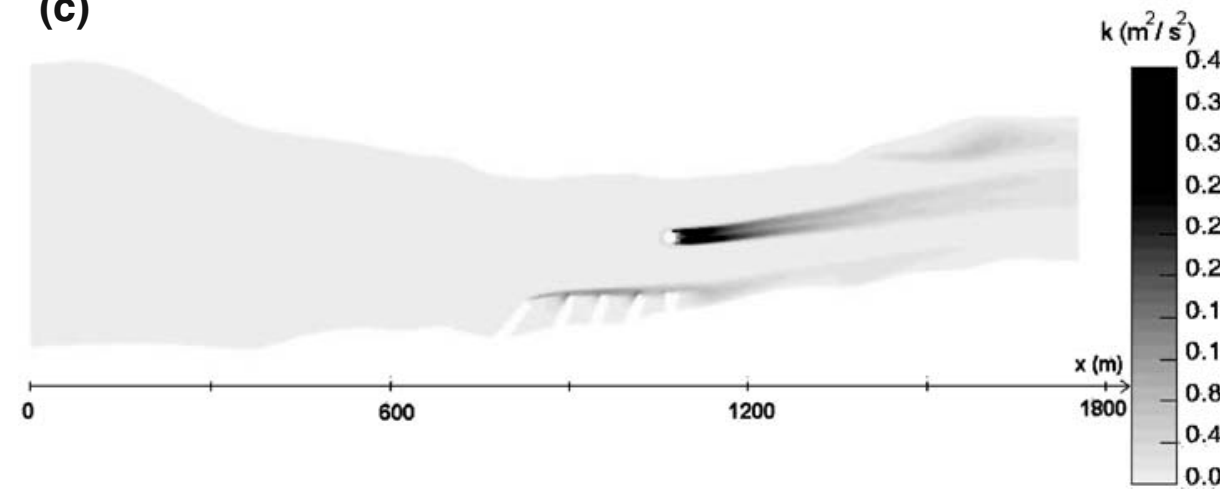

Fig. 16 Turbulence kinetic energy at the river surface for $\mathbf{a}$ no groynes, $\mathbf{b}$ five-groynes and $\mathbf{c}$ fourgroynes cases in $3 \mathrm{D}$ computations

$d_{2}$ resting on a bed of particles of diameter $d_{1}$ can be found by Eq. 12 as described in Julien (1998). Using the Shields curve and Eq. 12, the critical shear stress for medium gravels on top of coarse sand layer is estimated to be $4.7 \mathrm{~N} / \mathrm{m}^{2}$. The critical shear stress for a particle on the bank is not the same as for one on the bed. The relation between the critical shear stress for a particle on the bed and the bank can be found 


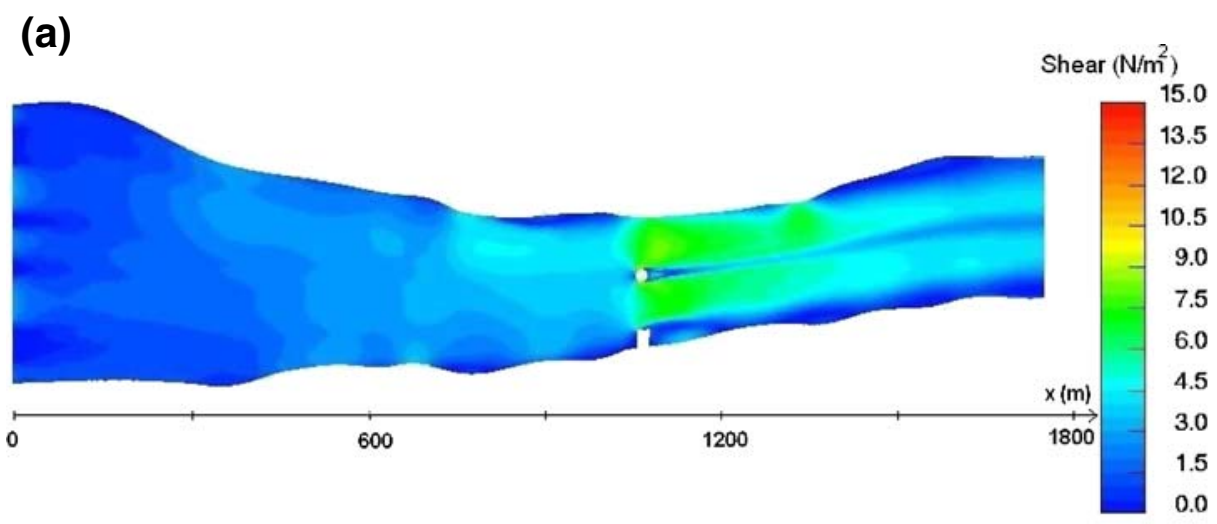

(b)
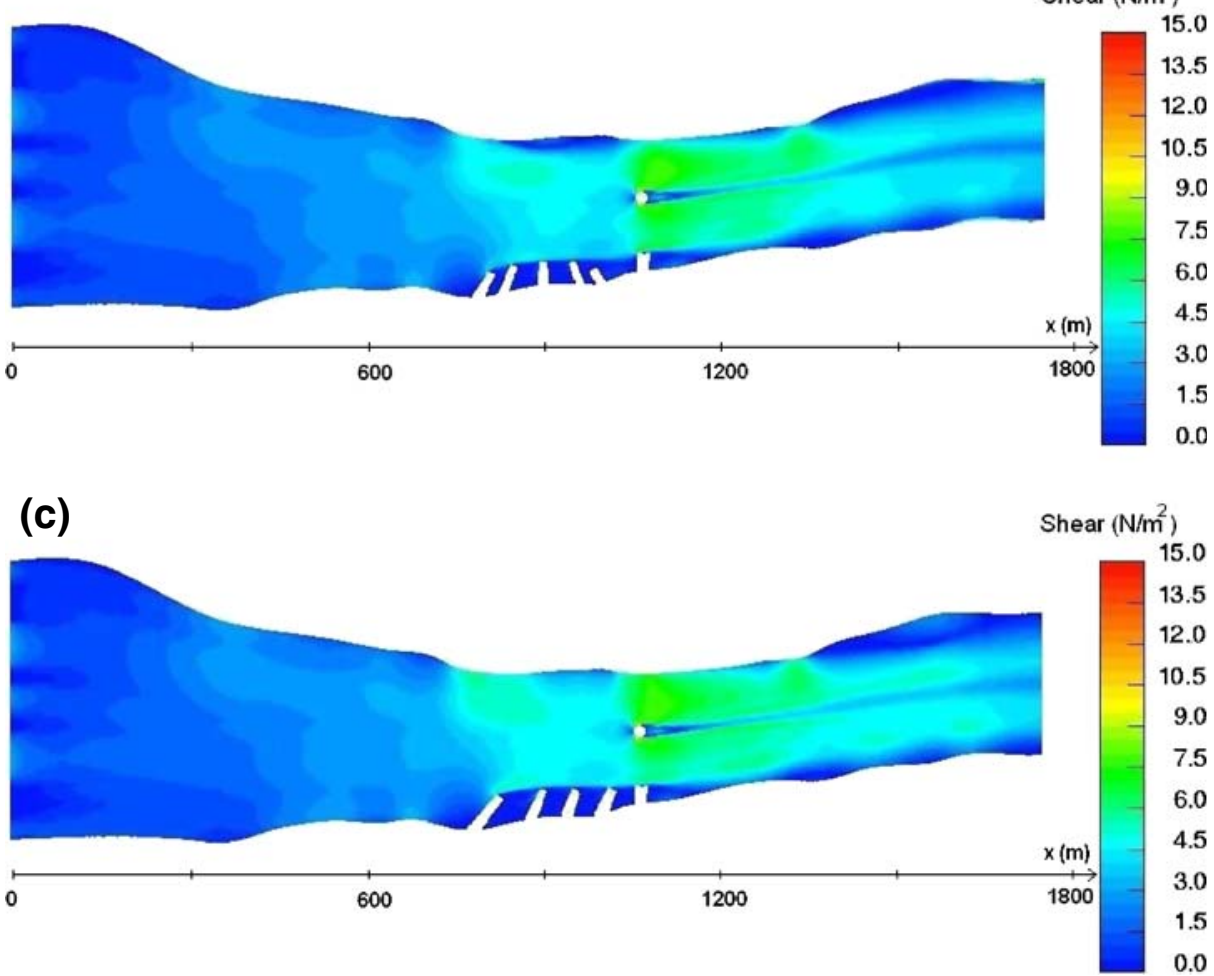

Fig. 17 Bed shear stress for a no groynes, $\mathbf{b}$ five-groynes and $\mathbf{c}$ four-groynes cases in 3D computations

by Eq. 13 as proposed by Lane (1955). The critical shear stress for the particle on the bank with bank angle $\theta=35^{\circ}$ is estimated as $1.4 \mathrm{~N} / \mathrm{m}^{2}$ and plotted in Fig. 18a.

The erosion rate at the right bank for the reach of the Sacramento River is plotted in Fig. 18c based on Partheniades (1965) and Hanson and Simon (2001) using the computed shear stresses and the critical shear stresses shown in Fig. 18a. 

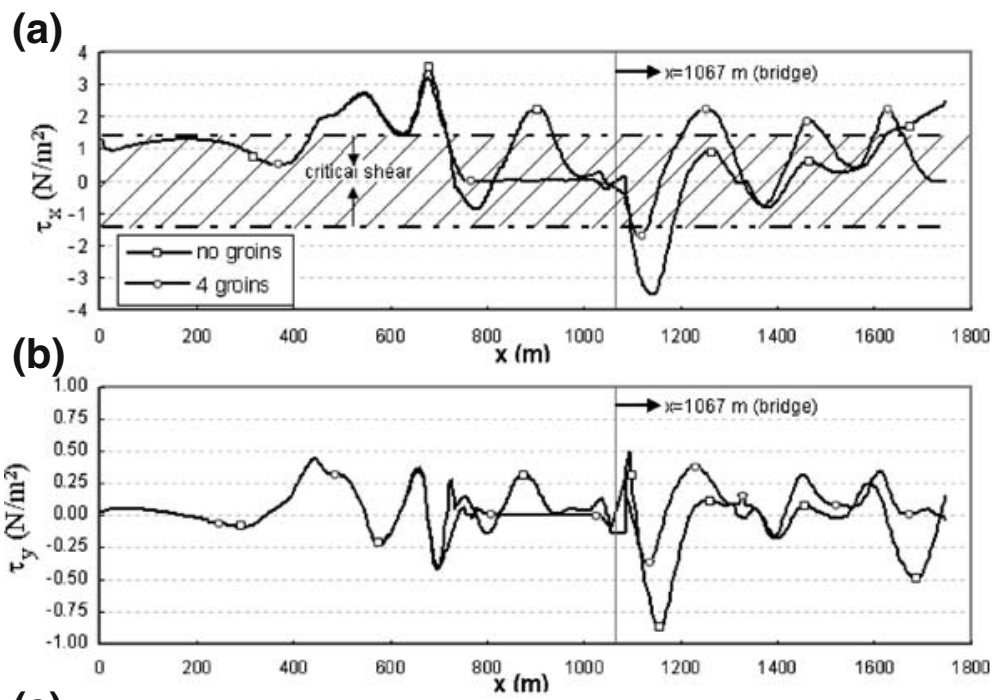

(c)

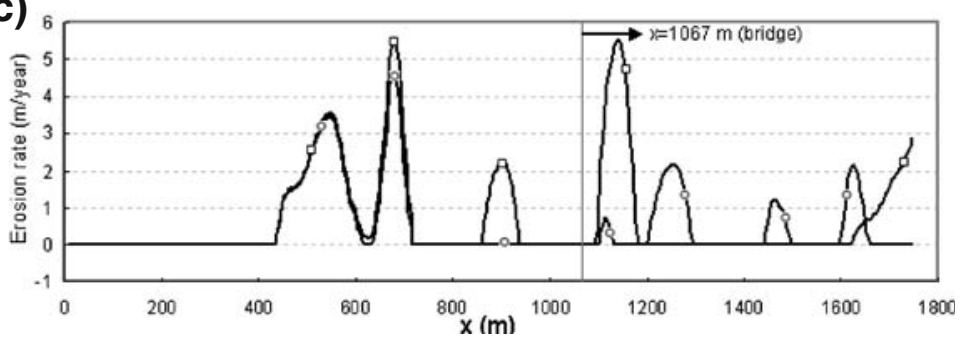

Fig. 18 Streamwise shear (a), spanwise shear (b) and erosion rate (c) at the right bank for no-groynes and four-groynes cases in 3D computation

The maximum erosion rate at the right bank of the river reach is predicted to be $5.6 \mathrm{~m} /$ year for the no-groyne case and $4.7 \mathrm{~m} /$ year for the four-groyne case. Near the bridge abutment, the bank erosion rate reaches the local maximum value for the nogroyne case at $x=902 \mathrm{~m}$ as $2.3 \mathrm{~m} /$ year and at $x=1140 \mathrm{~m}$ as $5.6 \mathrm{~m} /$ year. However, for the same region, the bank erosion rate is reduced to almost zero for the fourgroyne case. According to Fig. 18c, the deployment of the groynes reduces or halts the bank erosion where they are located and transfers a less severe problem further downstream. As has already been mentioned, these results have subsequently been confirmed by field observations conducted after the deployment of the four groynes in the river.

Finally, Ikeda et al. (1981) provides an alternative method of calculating bank erosion rate. For the reach of the Sacramento River under consideration, reachaveraged velocity is assumed to be equal to the average velocity at inlet, which is $1.3 \mathrm{~m} / \mathrm{s}$. The velocities along the streamwise and the spanwise directions calculated at the right bank for the no-groyne and the four-groyne cases in the 3D computations are plotted against streamwise distance in Fig. 19a, b. The velocities are averaged in the depthwise direction. With no groynes, the near-bank streamwise velocity exceeds the reach-averaged velocity in three regions: $446 \mathrm{~m}<x<601 \mathrm{~m}, 643 \mathrm{~m}<x<712 \mathrm{~m}$ 

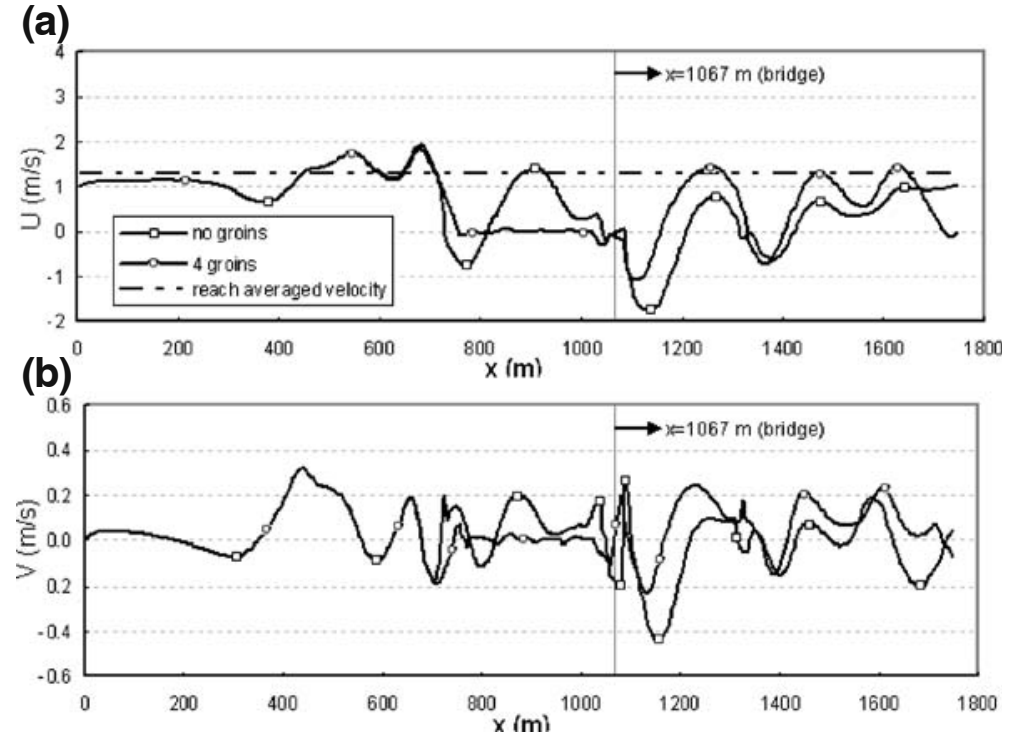

Fig. 19 Streamwise velocity (a) and spanwise velocity (b) at the right bank for no-groynes and fourgroynes cases in $3 \mathrm{D}$ computation

and $883 \mathrm{~m}<x<930 \mathrm{~m}$ upstream of the bridge abutment. When the five groynes are deployed, the streamwise and spanwise near-bank velocities are significantly reduced in the region $732 \mathrm{~m}<\mathrm{x}<1,067 \mathrm{~m}$ and so the possibility of bank erosion occurring at $883 \mathrm{~m}<x<930 \mathrm{~m}$ is reduced or eliminated. However, when four groynes are placed, the streamwise near-bank velocity exceeds the reach-averaged velocity at $1,228 \mathrm{~m}<x<1,285 \mathrm{~m}$ and at 1,609 $\mathrm{m}<x<1,649 \mathrm{~m}$ downstream of the bridge. The placement of four groynes, on the other hand, helps reduce the negative velocity peak at $x=1,134 \mathrm{~m}$. The negative velocity at $730 \mathrm{~m}<x<813 \mathrm{~m}$ for the no-groyne case in Fig. 19 was only observed near the bank in the $3 \mathrm{D}$ computation and is not observed with groynes (see Fig. 15). This negative velocity region near the bank was also not captured for the no-groyne case in the 2D computation (see Fig. 13).

\section{Conclusions}

Computer simulations were performed for a straight rectangular channel with one groyne, and the results were validated by comparisons with the experimental results of Rajaratnam and Nwachukwu (1983). Predictions of resultant velocity obtained with both $2 \mathrm{D}$ (depth averaged) and 3D approaches were quite close to the measured values upstream of the groyne but some differences were observed downstream of it where the flow was highly skewed and the secondary velocities were significant. Predictions of the bed shear stresses using the approaches of Pierce and Zimmerman (1973) and the Colebrook-White equation were also in accord with the experimental results. Modifications to the approach of Pierce and Zimmerman (1973) along the lines proposed by Johnston (1960) yielded improved predictions near the groyne where the $3 \mathrm{D}$ effects are significant. 
The predictions of the streamwise velocity for the reach of the Sacramento River with either four or five groynes obtained with the 2D and 3D approaches were compared with the measurements of the physical model of the same reach. The results for the streamwise depth-averaged velocities with groynes obtained in $2 \mathrm{D}$ and $3 \mathrm{D}$ computations were found to be quite similar. The predicted and measured profiles of mean velocity and contours of turbulence kinetic energy and bed shear stress were compared for both cases with and without groynes. The velocity magnitudes predicted by the $2 \mathrm{D}$ model were found to be close to the magnitudes predicted at the surface in the $3 \mathrm{D}$ model. Flow recirculation was observed downstream of the abutment near the right bank and downstream of the circular bridge pier in the main channel. Smaller recirculation zones were also obtained in the regions of flow between adjacent groynes. Enhanced turbulence activity was observed downstream of the circular bridge pier in the main channel, and downstream of the bridge abutment near the right bank. It was observed that the groynes limit the crosssectional flow area where they were located and cause the flow to accelerate in the main channel. This in turn causes higher bed shear stress and increases the possibility of erosion in the main channel downstream of where the groynes were located.

Finally, both the excess shear-stress method of Partheniades (1965) and the excess velocity method of Ikeda et al. (1981) were used to estimate the bank erosion rate. By applying the Partheniades method, the maximum erosion rate upstream of the bridge abutment on the right bank of the river reach was calculated to be $5.6 \mathrm{~m} / \mathrm{year}$ without groynes, and $4.7 \mathrm{~m} /$ year with four groynes. It was observed that the groyne structures considerably reduce bank erosion where they are located and transfer a less severe problem further downstream.

Open Access This article is distributed under the terms of the Creative Commons Attribution Noncommercial License which permits any noncommercial use, distribution, and reproduction in any medium, provided the original author(s) and source are credited.

\section{References}

ASCE Task Committee on Hydraulics, Bank Mechanics, and Modeling of River Width Adjustment (1998) River width adjustment. I: processes and mechanisms. J Hydraul Eng 124(9):881-902. doi:10.1061/(ASCE)0733-9429(1998)124:9(881)

Brice JC (1982) Stream channel stability assessment. Report No. FHWA/ RD-82/021, Federal Highway Administration, US Department of Transportation, Washington, D.C.

Celik I, Karatekin O (1997) Numerical experiments on application of richardson extrapolation with nonuniform grids. ASME J Fluid Eng 119:584-590. doi:10.1115/1.2819284

Darby SE, Thorne CR (1996) Stability analysis for steep, eroding, cohesive river banks. J Hydraul Eng 122:443-454. doi:10.1061/(ASCE)0733-9429(1996)122:8(443)

Darby SE, Alabyan AM, de Wiel MJV (2002) Numerical simulation of bank erosion and channel migration in meandering rivers. Water Resour Res 38(9):2.1-2.12

Duan G, Wang SSY, Jia Y (2001) The applications of the enhanced CCHE2D model to study the alluvial channel migration processes. J Hydraul Res IAHR 39:469-480

Ercan A, Younis BA (2008) Uncertainties in the prediction of flow in a long reach of the Sacramento River. Water and Environment Journal, Print ISSN 1747-6585, 2008

Flora KS (2003) Potential geomorphic impacts of bank stabilization measures along the Sacramento River near the Butte City bridge on route 162. M.S. Project, Dept. of Civil \& Environmental Engineering, University of California Davis

Hanson GJ, Simon A (2001) Erodibility of cohesive streambeds in the loess area of the midwestern USA. Hydrol Process 15(1):23-38. doi:10.1002/hyp.149 
Hardy RJ, Lane SN, Ferguson RI, Parsons DR (2003) Assessing the credibility of a series of computational fluid dynamic simulations of open channel flow. Hydrol Process 17(8):1539-1560. doi:10.1002/hyp.1198

Hasegawa K (1984) Hydraulic research on planimetric forms, bed topographies and flow in alluvial channels. PhD dissertation, Hokkaido Univ., Sapporo, Japan (in Japanese)

Hasegawa K (1989) Universal bank erosion coefficient for meandering rivers. J Hydrol Eng 115(4):744-765

Ikeda S (1982) Incipient motion of sand particles on side slopes. J Hydr Div Am Soc Civ Eng 108(HY1):95-114

Ikeda S, Parker G, Swai K (1981) Bend theory of river meanders. Part I. linear development. J Fluid Mech 112:363-377. doi:10.1017/S0022112081000451

Jang CL, Shimizu Y (2005) Numerical simulation of relatively wide, shallow channels with erodible banks. J Hydrol Eng 131(7):565-575. doi:10.1061/(ASCE)0733-9429(2005)131:7(565)

Johnston JP (1960) On the three dimensional turbulent boundary layer generated by secondary flow. J Basic Eng Trans ASME Ser D 82:233-248

Julien PY (1998) Incipient motion. Erosion and sedimentation. Cambridge University Press, Cambridge, pp 112-133

Lane EW (1955) Design of stable channels. Trans Am Soc Civ Eng 81(745):1-17

Lane SN, Bradbrook KF, Richards KS, Biron PA, Roy AG (2000) Secondary circulation cells in river channel confluences: measurement artefacts or coherent flow structures? Hydrol Process 14:2047-2071

Launder BE, Spalding DB (1972) Lectures in mathematical models of turbulence. Academic Press, London

Lawler DM (1992) Processes dominance in bank erosion systems, in lowland floodplain Rivers. In: Carling PA, Petts GE (eds) Wiley, New York, pp 117-143

Mishra SK, Lindsey WB (2000) Butte City bridge erosion control project. In: Proceedings of building partnership, ASCE, August 2000, Minneapolis, MN

Molinas A, Hafez YI (2000) Finite element surface model for flow around vertical wall abutments. J Fluids Struct 14:711-733. doi:10.1006/jfls.2000.0295

Molls T, Chaudhry MH (1995) Depth-averaged open-channel flow model. J Hydr Eng ASCE 121(6):453-465

Nagata N, Hosoda T, Muramoto Y (2000) Numerical analysis of river channel processes with bank erosion. J Hydraul Eng 126(4):243-252. doi:10.1061/(ASCE)0733-9429(2000)126:4(243)

Nanson GJ, Hickin EJ (1983) Channel migration and incision on the Beatton River. J Hydr Eng ASCE 109(3):327-337

Novikov A, Bagtzoglou AC (2006) Hydrodynamic model of the Lower Hudson River esturine system and its application for water quality management. Water Resour Manage 20:257-276. doi:10.1007/s11269-006-0320-9

Olsen NRB (2003) Three-dimensional CFD modeling of self- forming meandering channel. J Hydraul Eng 129(5):366-372. doi:10.1061/(ASCE)0733-9429(2003)129:5(366)

Parker G (1983) Theory of meander bend deformation, in river meandering. In: Proceeedings of the conference rivers, 83. ASCE, New York, pp 722-732

Partheniades E (1965) Erosion and deposition of cohesive soils. J Hydraul Div 91:105-139

Pierce FJ, Zimmerman BB (1973) Wall shear stress inference from two and three dimensional turbulent boundary layer velocity profiles. J Fluids Eng Trans ASME Ser D 95:61-67

Pizzuto JE, Meckelnburg TS (1989) Evaluation of a linear bank erosion equation. Water Resour Res 25(5):1005-1013. doi:10.1029/WR025i005p01005

Rajaratnam N, Nwachukwu B (1983) Flow near groin-like structures. J Hydraul Div 109(3):463-480. doi:10.1061/(ASCE)0733-9429(1983)109:3(463)

Rastogi AK, Rodi W (1978) Prediction of heat and mass transfer in open channels. J Hydraul Div 104:397-420

Roache PJ (1994) Perspective: a method for uniform reporting of grid refinement studies. ASME J Fluids Eng 116:405-413. doi:10.1115/1.2910291

Roache PJ (1997) Quantification of uncertainty in computational fluid dynamics. Annu Rev Fluid Mech 29:123-160. doi:10.1146/annurev.fluid.29.1.123

Shields A (1936) Application of similarity principles and turbulence research to bed load movement. California Institute of Technology, Pasadena, Pub. No. 167 (English Translation)

Singer MB, Dunne T (2001) Identifying eroding and depositional reaches of valley by analysis of suspended sediment transport in the Sacramento River, CA. Water Resour Res 37(12):33713381. doi:10.1029/2001WR000457 
Thangam S, Speziale CG (1992) Turbulent flow past a backward-facing step: a critical evaluation of two-equation models. AIAA J 30:1314-1320. doi:10.2514/3.11066

Thorne CR (1982) Process and mechanisms of river bank erosion, in gravel-bed rivers. In: Hey RD, Bathurst JC, Thorne CR (eds) Wiley, New York, pp 227-271

Tingsanchalli T, Maheswaran S (1990) 2-D depth-averaged flow computation near groyne. J Hydr Eng ASCE 116(1):71-86

Tsihrintzis VA, Madiedo EE (2000) Hydraulic resistance determination in marsh wetlands. Water Resour Manage 14:285-309. doi:10.1023/A:1008130827797

U.S Army Corps of Engineers (1983) Sacramento River and tributaries bank protection and erosion control investigation. California Sediment Transport Studies, Sacramento Dist., US Corps of Eng., Sacramento, CA 